\title{
User Perception of Bitcoin Usability and Security across Novice Users
}

\author{
Abdulla AlShamsi and Peter Andras \\ School of Computing and Mathematics \\ Keele University \\ Newcastle-under-Lyme, Staffordshire, UK \\ a.j.a.alshamsi@keele.ac.uk \\ p.andras@keele.ac.uk
}

\begin{abstract}
This paper investigates users' perceptions and experiences of an anonymous digital payment system (Bitcoin) and its influence on users in terms of usability and security in comparison to other non-anonymous payment systems such as credit/debit cards. This paper identifies users' perceptual differences in terms of usability and security. Two versions of user survey are used to collect data, which reveal significant differences in users' perceptions of credit/debit cards and Bitcoin. The usability attributes of both systems examined show that respondents perceive the usability of credit/debit cards to be higher than Bitcoin. This has a great negative influence on users' security perceptions of Bitcoin. We conclude that Bitcoin, as a crypto-currency, is still in its infancy and requires user education and a new way of thinking. The study recommends developing users' mental models to deepen developers' understanding of anonymous digital payment technology and improve user-centred design. We also make recommendations with respect to e-government services that may be developed relying on crypto-currencies.
\end{abstract}

Keywords: User perception; Bitcoin; Credit/Debit card; Usability; Security; Trade-off

\section{INTRODUCTION}

Bitcoin is the world's first new decentralized digital currency that depends on a decentralized peer-to-peer network to allow Internet users around the world to transact freely and anonymously without relying on governmental or third-party institutions. Bitcoin experts and researchers report that active Bitcoin users will number almost 5 million and the number of transactions will increase by 50\% by the end of 2019 (Bitcoin Stats, 2017). In the last two 
years, the popularity of Bitcoin has exploded. Its price jumped from nearly 572 U.S. dollars in August 2016 to about 4,700 U.S. dollars in August 2017, resulting in a huge surge in demand worldwide (Bitcoin.org, 2018). Regardless of the mixed opinions about the future of Bitcoin and the extreme volatility of Bitcoin's value over its short history, it has gained many supporters (BusinessInsider, 2018).

Bitcoin has novel features including decentralization, user anonymity and control, not seen in any previous digital payment systems. These unique features may have a great influence on how users and designers think about all cryptocurrency transactions in the near future (Churchill, 2015). Churchill (2015), in her article in Interaction magazine, emphasizes the importance of the underlying structure of Bitcoin (Blockchain) and how such innovative technology could be used widely in sectors other than finance. We found few studies that investigate user perceptions of Bitcoin usability and security. One of these studies investigates the sociological implications related to the emergence of Bitcoin and provides an anthropological opinion on Bitcoin users. The paper discusses user privacy, the role of miners, and the volatility of Bitcoin value (Maurer, Nelms, \& Swartz, 2013). The characteristics of Bitcoin users and user motivations are studied by analyzing Google Trends data (Yelowitz \& Wilson, 2015). The study finds that users' interest in using Bitcoin is driven by computer programming and illegal activity, but finds no support for political or investment motives. An interesting exploratory study interviewed three groups, end consumers, e-commerce merchants, and Bitcoin exchange employees, with differing levels of skill, to investigate usability, usefulness and subjective norm. The results reveal that most Bitcoin stakeholders perceive ease of use to be low and perceive its usefulness to vary according to group. The study claims that most interviewees agreed that Bitcoin had a promising future as a payment method (Baur, Bühler, Bick, \& Bonorden, 2015). Eskandari, Clark, Barrera, \& Stobert (2015) present a first look at the key management of Bitcoin by evaluating the most used Bitcoin 
wallets. The study concludes that poor usability of key management and malicious exchange causes Bitcoin users to lose money. The study highlights that poor usability and users' lack of knowledge of Bitcoin usage are the main influencers of security breaches. Gao, Clark, \& Lindqvist (2015), in their peer-reviewed study, examine adopters and non-adopters' perceptions of the cryptocurrency. The results reveal that both adopters and non-adopters misunderstand how Bitcoin actually works. The study states that people with no experience with Bitcoin find it too hard, or too scary, to use. A comprehensive survey and assessment of existing academic research into Bitcoin indicates that Bitcoin is an exceptional case where practice appears to be ahead of theory. Analysis of the academic research available shows a tremendous opportunity and need for future research into user attitudes and perception of Bitcoin (Bonneau et al., 2015).

Recently, the HCI community has started to explore areas of digital currency and discuss the value of cryptocurrency from users' points of view (Kaye, Vertesi, Ferreira, Brown, \& Perry, 2014). However, there is limited academic work on user-centred approaches to the exploration of Bitcoin's social aspects, system adoption, user attitudes or behaviours (Bohr \& Bashir, 2014; Gao et al., 2015; Krombholz, Judmayer, Gusenbauer, \& Weippl, 2016; Yelowitz et al., 2015). Some researchers agree that usability is key to increasing Bitcoin usage as a payment system, but there are many other concerns to overcome before that point. Balancing security and usability is one of the biggest challenges for the HCI community (Eskandari, 2015; Sas \& Khairuddin, 2015; Simpson, 2014).

Examination of the available literature shows no studies jointly addressing users' perceptions of Bitcoin usability and security. We found only a few good quality papers in journal level publication venues, with most papers published in symposiums, conferences and workshops. Accordingly, there is a need for good quality journal papers with in-depth analysis with a focus on users' perceptions of Bitcoin usability and security and the trade-off between them. 
The objective of this study is to carry out a user study, which not only provides deep insight into how users perceive the usability and security of Bitcoin, but also indicates the level of user interaction with the newly emerged decentralized anonymous digital currency system. This study provides concrete prescriptions for developing user-centred decentralized payment services that can be implemented by government entities. Governments around the world strive to promote their e-services, using the latest technology. Bitcoin, as a promising payment system, offers new approaches for governments by introducing Blockchain technology. Blockchain technology offers fast and cheap transactions, improves transparency, prevents fraud and increases trust among users. This study provides a clear picture of users' attitudes and opinions about Bitcoin to help e-service developers understand end-user perceptions in terms of usability and security.

This study investigates users' perceptions and experiences relating to secure and anonymous systems such as Bitcoin, compared with other current systems such as credit/debit cards. The main goal of this study is to investigate the trade-off between usability and security from a user perspective, in order to understand how users perceive the usability and security of an anonymous payment system. This study seeks a comprehensive understanding of how users interact with the anonymous payment system, what they perceive, and their experience in respect of usability and security. The study focuses on understanding users' requirements from an anonymous payment system and capturing their experiences of the usability and security, compared to credit/debit card users. The analysis of the results increases the knowledge in this field and deepens our understanding of user requirements with respects to usability and security. Additionally, the findings help e-government service designers to design more usable and secure payment systems based on user requirements of anonymous payment system. This research provides developers with a clear view of user opinion that may help in the development of new concepts or standards for e-government services, in terms of usability and 
security. The study presents a good chance to learn about aspects of Bitcoin which require further focus in order to enhance user satisfaction with applications to novel e-government services based on the use of crypto-currencies. The study also provides a theoretical foundation for academics and practical guidelines for service providers in dealing with the usability and security aspects of decentralized systems.

The paper addresses the following research question: "How does a secure and anonymous system such as Bitcoin influence user experience of usability and security compared to a nonanonymous payment system such as credit/debit cards"? .

This paper presents a comprehensive user study of the human computer interaction (HCI) aspects of the anonymous payment system. The goal is to understand users' interactions and capture their experiences in terms of usability and security, in comparison to their experience of the currently most-used non-anonymous payment systems. The research scope is users' perceptions of usability and security trade-off. Perceived novelty is outside this research scope as it is another dimension of the potential predictors of IT innovation adoption that explain how and why individuals adopt an IT innovation (Wells, Campbell, Valacich, \& Featherman, 2010).

\section{RELATED LITERATURE}

Bitcoin is a new type of currency that does not require any specific governmental authentication. There is a platform for this currency to thrive in the cyber world. Bitcoin is used for 130,000 transactions daily, and $\$ 3.5$ billion US exists in the current market (Krombholz et al., 2016). According to Bitcoin Stats (2017), daily trading in Bitcoin is around $\$ 151$ million US. The increase in the volume of Bitcoin trading indicates its growing popularity (Bonneau et al., 2015).

However, Bitcoin has had adverse effects on users. For example, a person lost a hard disk containing Bitcoins worth $£ 4$ million in landfill in Newport, UK (Hern, 2013). This leads to the question of whether a digital wallet is more secure than a credit/debit card, where a third 
party can protect users when money gets lost. Digital currency is legally unregulated, therefore, if the user dies, the currency dies too, as there is no ability to inherit Bitcoin (Brito \& Castillo, 2013). This is a practical downside of using Bitcoin compared to credit/debit cards.

Indeed, both the weaknesses and strengths in the areas of usability and security are derived from the very nature of the encryption of Bitcoin. Thus, it is necessary to explore the concept of Bitcoin as a currency before examining its usability and security aspects (Eskandari, 2015).

The traditional system of transaction via the Internet involves three parties, the payer, the payee and the bank. Hence the perceived security and perceived ease of use come at the cost of the need for service users to trust a third party (Sas \& Khairuddin, 2015). This dependency on a third party has led to an undermining of both security and usability. In terms of security, the third party holds sensitive financial information about both sides, which can be used illegally. In terms of usability, the third party is obliged to follow complicated bureaucratic processes for each international transaction which slows the speed of transactions (Singh, Chandavarkar, Arora, \& Agrawal, 2013). In order to overcome these two issues, e-commerce relies on crypto currency such as Bitcoin (Böhme, Christin, Edelman, \& Moore, 2015).

Bitcoin is a unique payment system using crypto currency (Yelowitz et al., 2015). It makes use of encryption techniques in order to regulate the generation of digital currency units and verify funds transferred (Reid \& Harrigan, 2013). This process is carried out independently, without the intervention of any bank. The main advantage of Bitcoin crypto currency is that it provides a vent for personal wealth which is beyond confiscation or restriction. It is considered a useful medium of exchange in digital form, secured by cryptography, which not only secures transactions but also controls the generation of currency units.

Bitcoin was established in 2008 by Satoshi Nakamoto. It uses open source software which can be downloaded directly from the Internet. Users require a cell phone, laptop or other electronic medium to download the software and make transactions as Bitcoins are connected 
to particular IP addresses (Mainelli \& Smith, 2015). It is a peer-to-peer transaction medium (Bamert, Decker, Elsen, Wattenhofer, \& Welten, 2013). Each transaction made with Bitcoin is verified at the network nodes and documented in Blockchain, which is a publicly distributed ledger (Moser, Bohme, \& Breuker, 2013). As there is no bank or other third party needed to carry out the transaction it is a decentralized system, unlike other payment or monetary systems which are centralized under the authority of banks (Nakamoto, 2008).

\subsection{Rethinking government e-services}

Governments around the world are adopting and implementing the latest information computer technology (ICT) in order to provide a wide range of services to citizens (Kotamraju \& van der Geest, 2012). Recently, many governments have changed from traditional service delivery platforms to electronic platforms which allow users to take on new roles in the delivery of services. The transactional journey of the government-citizen relationship needs to focus on easy-to-use interface design, which is critical to the successful adoption and use of applications (de Jong \& Lentz, 2006; Taylor, Zhang, \& Adipat, 2009). Such services aim to enhance the accessibility of services, while reducing the cost of delivery and the delay. However, these benefits cannot be obtained without continued monitoring of the e-government services to identify the benefit to the end user (Papadomichelaki \& Mentzas, 2012; Aichholzer, 2009).

The effectiveness of e-government implementation is challenged in the literature. Ruba, Hartmut, \& Viswanath, 2014 contend that there is lack of citizen-centric design in many egovernment services, resulting in the under-utilisation of e-government initiatives. Additionally, since there is a great deal of sensitivity and a need for confidentiality of information in the e-government framework, it is imperative to ensure security and protection. As Choi, Ae Chun, \& Cho, 2014 argue, security and trusted information should be key issues that are adopted in order to prevent unauthorised disclosure or leakage of secret information. 
Lesemann, Woletz, \& Koerber, 2007 say that usability issues need to be examined in the design of new functions and services on any platform, to ensure an enjoyable user experience. Alberto, 2010 presents an excellent conclusion to the need for usability and security, claiming that IT-enabled service interactions must meet users' expectations. Therefore, e-government services must be designed based on users' backgrounds, levels of knowledge, skills and contexts of use in order for there to be satisfactory services (Raptis, Tselios, Kjeldskov, \& Skov, 2013).

There have recently been government efforts to adopt a new revolutionary emerging technology that offers fast, secure, efficient and transparent services. This emerging technology is Blockchain, a collaborative technology with a great ability to improve online government services. Blockchain and its underlying technology presents opportunities for all kinds of public services to provide tools that cut errors, reduce costs, increase security, avoid fraud and enhance productivity. This promising technology could revolutionize the way citizens interact and transact with e-government over the Internet. Blockchain technology opens doors for many potential applications including tax collection, identity management, local (or national) digital currencies, property and land registry, and other government records (Boucher, Nascimento, \& Kritikos, 2017).

Government experts have found that Blockchain technology brings many benefits and contributes to the development of many aspects of public service. Countries including Estonia, Georgia, India, France and Dubai are competing to introduce Blockchain technology to their governmental applications. Estonia for example, has been testing the technology since 2008, and in 2012 started to use Blockchain technology in a number of government activities such as national health registries and judicial services (Mainelli \& Smith, 2015). Dubai Land Department has announced on October 2017, that it is the world's first government entity to adopt the Blockchain technology to its operations (Wirtschaftsuniversität Wien, 2017). 
However, the development of Blockchain technology has both opportunities and risks. It can change the way e-services for citizens are delivered and managed, but the lack of mature Blockchain applications in other fields is a problem. Therefore, we need a more thorough understanding of citizens' needs and expectations about such technologies, in terms of usability and security (Boucher et al., 2017).

\subsection{Current payment systems and Bitcoin}

The use of debit and credit cards has increased significantly, but it involves a third party, a bank, to authenticate each transaction. The method of transaction using debit/credit cards involves a series of authentication steps (Goldfeder, Bonneau, Felten, Kroll, \& Narayanan, 2014). Authentication processes occur between the service user, or payer, and the bank, between the merchant, or receiver, and the bank, and between the payer and the receiver.

According to Plassaras, 2013, online transactions are mainly completed using debit/credit cards. This involves the service user sending details of their card over the Internet to be accessed by the bank. The majority of customers who perform transactions online are worried about hacking or their personal details being used by unauthorized personnel. The involvement of a third party for a successful transaction undermines the security of the transaction process and makes it more cumbersome (Herrera-joancomart, 2015).

Bitcoin, on the other hand, is less cumbersome as the transaction is carried out directly between users with no involvement of a third party or external agency (Herrera-joancomart, 2015). According to its founder, (Nakamoto, 2008), Bitcoin gained immense popularity due to its high level of perceived security.

\subsection{User perception of Bitcoin usability}


The Bitcoin payment system has various advantages over other payment systems such as payment by credit/debit cards, as reported by Sas \& Khairuddin (2015), who undertook an exploratory study collecting data from nine interviewees about their motivation for using Bitcoin. They indicated that the most important characteristic is its decentralization as a method of payment, and the entire process not being controlled by a single authority. Each of the machines that process transactions and mine coins work together to form a network. Hence, no monetary policy can be decided on. According to Wankmueller (2005), conventional payment systems involve opening bank accounts, and there is a need for a merchant account which makes the system expensive. In the Bitcoin system, users can set up a Bitcoin address in seconds and no money is charged (Barber, Boyen, Shi, \& Uzun, 2012).

Bitcoin users can set up more than one Bitcoin address. The most advantageous usability element of Bitcoin is that the payment system is transparent (Popescu, 2014). It stores each detail of a transaction within a network across the Internet. The details are stored in a form of general ledger known as the Blockchain. Anyone can detect the number of Bitcoins available at a particular Bitcoin address, however they are not able to detect who the Bitcoins belong to (Plassaras, 2013). Users can take appropriate measures to ensure the activities they perform are opaque. According to Miers, Garman, Green, and Rubin (2013), users should use various Bitcoin addresses rather than using the same address consistently, and not transfer large numbers of Bitcoin to a single address.

Androulaki, Karame, Roeschlin, Scherer, and Capkun (2013) observe that merchants are charged an amount for each debit/credit card transaction, which is a significant cost to a company. Customers who make payment via these cards are also bound to pay certain charges for using the services of a bank (Popescu, 2014). This sometimes dissatisfies customers despite the ease of making a transaction not in cash. Transactions carried out internationally via the card system have significantly increased transaction charges, which makes merchants 
dissatisfied. In contrast, Bitcoin has no such transaction charges. Any transaction between users, whether overseas or within the same country, is not subject to any charges, and the number of transactions that can be made per day is not limited. The major disadvantage of debit/credit card payment is that the money transferred might take as long as two days. However, the biggest difficulty faced by users of Bitcoin is that Bitcoins are non-refundable. According to Luther and Olson (2013), once Bitcoins are sent to the recipient they are gone from the transferee forever and are not refundable. On the other hand, payments made via card do not have this limitation. The money transferred is refundable and reaches the payer within a couple of days. The payer can also terminate a credit/debit card transaction (Moser et al., 2013)

Among the various clients of Bitcoin (i.e. full clients, headers-only clients, signing-only clients, thin clients, and mining clients) questions of usability do exist. Absolute trust is demanded of the provider of the eWallet for two reasons; they know the history of the user and monitor the users' Bitcoin. There is no overt process to assure the user that the eWallet provider has the sum that appears as their balance supported by reserved Bitcoin (Ben-Sasson et al., 2014). The eWallet provider can also become a victim due to theft, loss or malicious takeover of Bitcoin, leading to a loss of funds for the customers (Ober, Katzenbeisser, \& Hamacher, 2013). Nonetheless, usability is buttressed through QR codes, Bitcoin URIs, deterministic wallets and brain wallets. By applying theses digital services, the experience and attitude of Bitcoin users about the usability of Bitcoin could become similar to traditional credit/debit cards (Meiklejohn et al., 2013).

Recent studies show that the Bitcoin system is complex to use and there are misconceptions about how it works (Gao et al., 2015; Yelowitz et al., 2015). This may affect users' perceptions of the Bitcoin payment system in comparison to other payment systems (Baur et al., 2015; Jose, 2016; Yelowitz \& Wilson, 2015). Learnability is the most important usability attribute 
(Nielsen, 2005). Any system should be easy to learn so that the user can rapidly accomplish basic tasks, first time, using the system. Learnability is considered an important usability aspect for novice users who may be put off using the system if it is not easy to learn (Dzida, Herda, \& Itzfeldt, 1978). Evidence from recent studies shows that ease of learning perception has a significant effect on user attitudes to e-payment systems and the likelihood of errors. The system is considered more efficient and effective if the user is able to accomplish tasks or transactions with speed and simplicity.

Some researchers compare Bitcoin wallet interfaces and find serious issues in terms of complexity and lack of help (Simpson, 2014; Skudnov, 2012). Other studies state that there are concerns about Bitcoin transaction speeds, with the average time needed to confirm transactions being about 25 minutes (Athey, Parashkevov, Sarukkai, \& Xia, 2016; Bonneau et al., 2015). The time taken to confirm transactions delays the operation of selling and buying, while credit/debit card transactions are confirmed in less time (Barber et al., 2012; Herrerajoancomart, 2015; Singh et al., 2013; Skudnov, 2012). Nielsen, 2012 states that if the delay time is longer than ten seconds, users switch to other faster alternatives or applications. The literature review shows some evidence of memorability concerns for users related to Bitcoin addresses and login IDs for Bitcoin clients, which are worse than computer-generated IDs. Users find it hard to remember these login IDs and addresses (Barber et al., 2012; Luther \& Olson, 2013; Skudnov, 2012). Accordingly, users might find less memorability attributes in Bitcoin payment systems than credit cards. Obviously, Bitcoin transactions cannot be reversed and access can't be restored. Therefore, a mistaken Bitcoin transaction or a lost credential results in a loss of user funds (Böhme et al., 2015; Singh et al., 2013). Thus, the user might perceive more unrecoverable errors with Bitcoin than credit/debit cards. Bitcoin, as an emerging complex technology, is not yet systematically explored and the information available is insufficient to give users a full picture of how it works. A few studies indicate an absence of 
complete or reliable information about most Bitcoin exchanges and Bitcoin clients (Böhme et al., 2015; Eskandari et al., 2015; Goldfeder et al., 2014; Jose, 2016). Users need access to a help system in any application in order to learn the system functions and features.

User satisfaction is another important dimension of usability. Research shows that the overall impression and experience of users is influenced by other usability attributes such as learnability, efficiency, help and errors. These usability attributes affect the overall user satisfaction of the system studied.

The usability attributes mentioned in the literature should be assessed as a whole subset, unless domain specific studies suggest otherwise. Studying all these attributes gives a sufficient indicator of the overall usability of the studied system rather than assessing one or two aspects that may lead to unreliable conclusions about overall usability.

\subsection{User perception of Bitcoin security}

Bitcoins are considered pseudonymous (Reid \& Harrigan, 2013), which means that the funds are not associated with real-world identities but Bitcoin IP addresses (Koshy, Koshy, \& McDaniel, 2014). The Bitcoin users who are supposedly the owners of the Bitcoin addresses cannot be identified explicitly, but the transactions they make are recorded in the Blockchain which is public (Garcia, Tessone, Mavrodiev, \& Perony, 2014). Other users can see the number of Bitcoins that are transferred or received by a single Bitcoin address but are unable to identify who the owner is (Mainelli \& Smith, 2015). Transactions can be linked by observing the times and types of transaction. If it can be observed that a transaction includes coins from various inputs, there is a common owner to those inputs (Yelowitz et al., 2015). According to Reid and Harrigan (2013), when Bitcoins are traded for traditional currencies, it is important that the personal information of the owner is collected, and that this is compulsory under the law of the relevant country. In order to increase financial privacy, owners can generate new addresses for each Bitcoin transaction (Brito \& Castillo, 2013). Each transaction requires a single passphrase, 
which could help in tracking all transactions made by a single owner (Herrera-joancomart, 2015). This helps in securing the user's identity as the public is unable to identify which transactions are made. As the identity or any personal information is not accessed by any third party agent, such as a bank, and information is not stored on servers, there is no possibility of hackers accessing the personal information of Bitcoin users or making fraudulent transactions. According to Androulaki et al. (2013), the use of debit/credit cards over the Internet poses a significant threat for users. Hackers can hack security passwords or access PIN numbers, and make illegal transactions (Krombholz et al., 2016). Users often experience or perceive a lack of privacy and confidentiality in transaction information, and are therefore afraid of making online transactions (Yermack, 2013).

Security is considered a significant barrier for online users and can have a great influence on the use of online applications. Generally, user confidence in technology is greatly weakened if that technology is not supported by an accredited organization or legal authority. Therefore, security could be a determinant of users' decisions to use e-payment systems. With Bitcoin currency being a novel decentralized digital currency, and having some legality concerns, users might be less able to use protection effectively (Coutu, 2014; Gao et al., 2015). Also, poor usability of security functions and features may put the security of the system at risk. This can lead to a misconception among users that security is not important for them and they can ignore or try to bypass it (Braz, Seffah, \& Raihi, 2007). Some researchers, and standards organizations, identify other viewpoints on usability, and include security as a characteristic of usability (Abran, Khelifi, \& Suryn, 2003). Lack of usability and system complexity may cause security exposure directly and make users avoid the issue by bypassing the security mechanisms, even when the intention is to comply with the security mechanism.

The literature indicates that Bitcoin has earned immense popularity from 2008 over credit and debit cards due to the higher privacy offered by Bitcoin wallets. Due to the very nature of 
Bitcoin as an encrypted currency, it eliminates third party involvement. There is no need for the authentication steps imposed by governments or mathematical processes which can be manipulated illegally.

\subsection{Conclusion}

As this field is brand new (since 2008), this study is unique. It aims to explore the attitudes and opinions of users related to security and usability aspects, and pave the way for better ways of increasing end user perception of the usability and security of Bitcoin. To the best of our knowledge, there has not been any empirical research comparing anonymous and nonanonymous payment systems. With this paper, we contribute to the HCI field by means of an exploratory, mixed qualitative and quantitative approach using survey questionnaires. This study helps narrow the gap in research by investigating Bitcoin users' perceptions of usability and security and recommending appropriate guidelines to help developers understand Bitcoin users' need.

The findings help significant aspects of usability and security to be identified so that appropriate guidelines can be formulated to support and promote the use of Bitcoin payment systems. Furthermore, the results contribute to e-governments, banking institutions, online transaction providers, and developers by uncovering Bitcoin users' concerns and views about using Bitcoin payment systems, thereby enabling them improve systems based on user requirements.

\section{METHODOLOGY}

This paper aims to present a comprehensive user study covering the human computer interaction (HCI) aspects of the Bitcoin payment system. It examines novice smartphone users' perceptions and experiences of an anonymous, secure, digital payment system (Bitcoin) in 
comparison to the most used payment system (credit/debit cards), bringing insight into user experience of Bitcoin in terms of usability and security. The findings of the survey are important and contribute to HCI community understanding of how users experience, and feel about, the usability and security aspects of crypto-currency digital payment systems. Before we describe the methodology, we must outline the research hypotheses. The hypotheses, shown in Table 1: Research Hypotheses below, are based on the research questions and the usability guidelines of Nielsen (2005). They explore users' perceptions of the Bitcoin payment system environment. To ascertain high level opinions, we designed two online survey questionnaires to compare users' perceptions of anonymous and non-anonymous payment systems. We explored the usability and security features which could influence users' perceptions. This allowed us to compare users' opinions of anonymous and non-anonymous systems in terms of the usability and security aspects. Evidence from previous studies specifies that usability is a key element in determining system or service quality (Hornbæk \& Law, 2007; Johnson \& Willey, 2011; Leon et al., 2011; Nielsen, 2005), and ensuring user engagement. Usability can directly impact users' perceptions, opinions and attitudes (Lee \& Koubek, 2010). To understand how users perceive usability in an anonymous system, five usability attributes are included in the hypotheses which assess and capture user experience and opinion. These usability attributes are learnability, memorability, efficiency, error and help. In order to keep the hypotheses simple, we assume there is no difference between user attitudes towards Bitcoin use and the use of credit/debit cards. Then we explore the extent to which these default hypotheses are valid. The hypotheses are as follows.

Table 1: Research Hypotheses

\begin{tabular}{ll}
\hline$\#$ & Research Hypothesis \\
\hline H1 & Bitcoin and credit/debit card users perceive no difference in term of learnability. \\
\hline
\end{tabular}


H2 Bitcoin and credit/debit card users perceive no difference in term of efficiency (speed, accuracy, micropayments).

H3 Bitcoin and credit/debit card users perceive no difference in term of memorability (used occasionally).

H4 Bitcoin and credit/debit card users perceive no difference in term of error and recoverability.

H5 Bitcoin and credit/debit card users perceive no difference in term of help and documentation.

H6 Bitcoin and credit/debit card users perceive no difference in term of security.

H7 Bitcoin and credit/debit card users perceive no difference in term of satisfaction.

To accomplish the study objectives, two versions of a survey were designed to capture smartphone users' insights and experiences of each payment system. Both surveys were conducted online, separately, between January and March 2017. This method is in line with previous studies of usability and security practices. The findings of the literature review are used to identify which usability and security features capture users' perceptions when they interact with the payment systems. Both surveys examine user experience with an emphasis on the usability and security features of each payment system. Nielsen's usability guidelines (Nielsen, 2005), and security standards such as ISO/IEC 27002 and ISO/IEC 27001 for security (Candiwan, Beninda, \& Priyadi, 2016), are widely used, and their practicality has been proved by a number of studies. Since a number of scholars have proved the validity of these guidelines in capturing user perceptions of usability and security, we extend and redesign these guidelines to fit the specific requirements of the systems reviewed, with a detailed emphasis on the aspects of usability and security. The questions in both surveys are designed based on these guidelines. There are slight differences in the number of questions and survey design of each questionnaire to tailor them to each payment system. The questions used in the Bitcoin survey form the basis of the usability and security questionnaire in the credit and debit card survey. For the usability features, the questions are designed based on Nielsen's usability guidelines (Nielsen, 2005). Usability is divided into five sub-categories, learnability, memorability, efficiency, error and 
help, to give a broad view of the usability of the systems reviewed and make later evaluation easier. General questions are designed to capture users' experiences of the security features based on the available functions of the systems reviewed with an emphasis on authentication, confidentiality, integrity, backup and storage. Satisfaction is the third and final section of each survey, designed to measure the general satisfaction of the participants. Both surveys are designed with both closed and open-ended questions.

In both surveys participants are asked to respond on a five-point Likert scale, indicating their level of agreement with statements ( strongly agree $=5$; strongly disagree $=1$ ). An odd number of responses allows for a neutral answer (neither agree nor disagree) in the middle, so the respondents don't have to select a positive (agree) or negative (disagree) option. The quantitative results obtained from the five-point Likert scale can be easily collected and statistically analyzed. Both surveys were piloted and non-author respondents went through the usability and security questionnaires.

This study went through a standard ethical review process at Keele University (Research Ethics Committee's approval number ERP1289). Two different sets of recruiting material and screening questionnaire were created for the two versions of the survey. The procedures and recruitment processes for each survey are described in detail in the next sections.

\subsection{Bitcoin survey}

Survey participants were limited to undergraduate students studying at Keele University, over the age of 18, with a smartphone, with basic knowledge of using Bitcoin digital currency, willing to participate in the study. In the first part of the study, participants were recruited on the university campus via mailing lists and flyers in January 2017. An invitation email was sent to candidates along with a pre-survey questionnaire and consent form. In the pre-survey questionnaire, we asked the participants to rate themselves on their knowledge of cryptocurrencies. This was done in order to select participants who had basic or no knowledge 
of Bitcoin currency, as the study objective is to capture novice users' perceptions. The invitation email explicitly stated that we were conducting a study on digital currency and payment systems and were interested in candidates willing to experience crypto-currency payment systems and undertake tasks using their smartphones. Candidates were made aware that an allocated amount of Bitcoin currency would be transferred to them $(0.040$ Bitcoin $\approx £ 35$ at that time) to use after successfully completing the assigned tasks. Interested candidates were asked to fill in a pre-survey questionnaire to help us select appropriate candidates based on predetermined criteria. The pre-survey questionnaire was designed to collect demographic information such as age, gender, education level, and familiarity with Bitcoin clients (wallets) and smartphones. The screening survey was successfully completed by 27 students, and 25 candidates were selected to proceed with the study based on the study criteria. Three of the participants were later withdrawn from the study because of legality concerns about Bitcoin in the UK.

In stage two of the Bitcoin survey, 22 participants were asked to perform a set of practical tasks on the Bitcoin eWallet, typical of those users need to carry out to transact with Bitcoin. The goal was to allow respondents to perform tasks in a real-life context to give them the freedom of an uncontrolled environment and increase their understanding of Bitcoin. This would indicate the user's level of interaction with the system and give insight into the participant's perception of usability and security. The tasks were appropriate for the participants to perform in the study. Time and task length were considered, and a clear description given by the researchers in order to avoid any misunderstanding or misinterpretation. All the tasks were thoroughly checked and pre-tested in a pilot study.

To complete the tasks, the candidates were advised to use Blockchain.info as the hosted wallet provider and to watch the tutorial video before starting the tasks. The choice of this hosted wallet was due to the popularity of Blockchain.info and it is accessibility from various 
smart mobile devices. Blockchain.info is one of the most used mobile Bitcoin applications that do not require much storage, network bandwidth or computing power. It is one of the leading Bitcoin eWallets, providing end-to-end encryption for users, allowing them to experience secure transactions with greater privacy and less third party surveillance, protecting their keys and Bitcoins from sniffers (Eskandari et al., 2015).

All the participants received task sheets by email and were instructed to do the tasks and send them back to the researcher in order to fulfil the survey objectives. All the tasks were carefully checked and pre-tested in the pilot study. The tasks assigned to participants were:

T1: Configure a new Bitcoin account: participants had to navigate to the Blockchain.info site and set up a new wallet by providing an email address.

T2: After successfully configuring the wallet and obtaining a wallet ID, the participants had to create a new Bitcoin receiving address and write it down carefully on the task sheet. A Bitcoin receiving address can be shared with others to receive Bitcoin directly to a wallet. The Bitcoin receiving address changes with every payment.

T3: The third task was locating and setting up auto logout options, to automatically log out of their wallet after five minutes of inactivity, and write the steps on the tasks sheet. This task was given to participants to allow them to experience one of the security features.

T4: Participants were asked in the fourth task to change their login passwords and write the steps on the task sheet.

T5: Participants were asked to get their backup recovery phrase, check the online help available with this task, and write the steps on the task sheet. The recovery phrase can be used to restore all unused Bitcoins in the case of a lost password or a loss of service at Blockchain. The recovery phrase never changes and recovers all existing Bitcoins and newly received funds in the wallet. Participants were asked to comment on the number of words 
(phrases) generated automatically when conducting this step without mentioning or writing the phrases on the task sheet.

T6: Participants were advised to navigate Blockchain.info, experience the features and functions available to users and comment on their overall experience and what they most liked and disliked about using Bitcoin, clarifying their responses.

Participants were asked to return the filled in task sheets to the researcher, after double checking their receiving Bitcoin address. Participants were also advised to contact the researcher if they needed any help with the tasks.

All participants were given one week to do the tasks and return the sheets to the researcher. After they had successfully completed the tasks, the researcher sent 0.040 Bitcoin $(\approx £ 35)$ to each participant who provided a valid Bitcoin address. When all the participants confirmed that they had received the Bitcoins in their wallets, they were advised to use this amount to buy any online items they wanted. The participants were given the freedom to use this amount of Bitcoins in any online store accepting Bitcoin digital money, transfer it to friend or withdraw cash from any available Bitcoin cash machine. A map of all Bitcoin cash machines was sent to the participants. This was important to ensure that the participants felt in control of their experience when transacting with Bitcoin digital money in a real environment, and kept researcher interference to a minimum. Nielsen (1992) recommends observing how users interact with systems in their natural environments and giving them the freedom to experience the system without any interference.

In Stage three of the Bitcoin survey, the 22 participants who successfully completed Bitcoin tasks were invited to fill out a web-based survey questionnaire hosted by Survey Monkey (www.surveymonkey.com). This consisted of closed and open-ended questions in three sections, usability, security and satisfaction. Usability was further divided into five aspects based on Nielsen's usability guidelines (Nielsen, 2005), learnability, memorability, efficiency, 
error and help. Each section of the survey was designed to capture the participants' views of Bitcoin use in terms of usability and security. Each section of the survey consisted of sets of questions that captured the end users' views of the Bitcoin client. The Blockchain.info client wallet was revised based on its capability and used as inspiration for the design of the survey questionnaire, with an emphasis on usability and security features as shown in Appendix A.

\subsection{Credit and debit card survey}

The credit/debit card questionnaire was distributed online using Survey Monkey (www.surveymonkey.com). Keele University undergraduate students were contacted using internal e-mail and flyers. The invitation email explicitly stated that the participants needed to be over the age of 18 , have a debit or credit card and had used a smart mobile phone to purchase items online with the credit/debit card in the last six months. Participants were offered entry into a draw for a $£ 30$ gift voucher in return for filling in and submitting the survey.

The study included 33 undergraduate students, who are over the age of 18 and had used debit/credit card in the last six months. The questions were revised and reviewed by the authors to improve the construct validity. The participants were asked the extent to which they agreed with various statements, each one scored on a five-point Likert scale $(1=$ strongly disagree; 2 = disagree; $3=$ neutral; $4=$ agree; and $5=$ strongly agree). The five point Likert scale has become the norm in much research work because it offers sufficient choice and is easy to respond to. However, research has confirmed that more than five points in a Likert scale confuses respondents.

The questionnaire contained a few nominally scaled background questions. These questions sought information on demographics, smartphone use, and online purchases. The survey investigated the respondents' previous experiences and perceptions of using credit/debit cards in terms of usability and security. The survey was divided into three main sections, usability, security and satisfaction. The usability section was further divided into five sub-categories, 
learnability, memorability, efficiency, error, and help, as with the Bitcoin survey. Each section was designed to capture the participants' opinions about credit/debit card features and capabilities. Each section of the survey questionnaire assessed, in depth, with the emphasis on the features that may influence users' perceptions of usability and security as shown in Appendix B. These questions were carefully designed based on the credit/debit card features available that can help us to capture the participants' experiences and opinions and how they perceived the usability-security trade-off.

\section{DATA ANALYSIS}

The reliability of the questionnaire design was verified by Cronbach's alpha (overall=.876; learnability $=.857$; efficiency $=.847$; error $=.875$; memorability $=.844$; help=.852; security $=.868$; satisfaction=.860). The reliability test confirmed that the questionnaire design had satisfactory reliability with a Cronbach's alpha above 0.7 .

The data from the questionnaires was processed and analysed statistically, using a nonparametric analysis (Mann Whitney test) as suggested by Siegel (1956) to compare the views and opinions of the two groups (credit/debit card users versus Bitcoin users). This test is useful for a small sample size where the data are not normally distributed. The Mann-Whitney U-test does not make any assumptions related to the distribution. The logic behind the Mann-Whitney U-test is to rank the data for each situation, and examine the differences of the two rank totals (Gibbons \& 1938-, 1976).

Effect size was used to identify precisely how large the effects in the data really were. Effect size is a way of quantifying the size of the difference between two groups. Cohen's effect size estimates were used to interpret the meaning of the " $r$ " score in the data. Cohen classifies of effect size as 0.1 (small effect), 0.3 (moderate effect) and 0.5 or above (large effect) (Cohen J., 1992). 
To indicate whether the two systems had a difference in overall perception of usability and security, the Mann Whitney U-test was conducted with the two payment systems as independent variables and usability and security perception as dependent variables.

Statistical analysis of the data was conducted using the Statistical Package for Social Science (SPSS) for Windows (Version 13). The significant value (P) was pre-defined as less than 0.05.

\section{RESULTS}

\subsection{Demographics}

The total sample size participating in the Bitcoin study, after filtering, was 22 participants. Of these, $78 \%$ claimed to be male, $22 \%$ claimed to be female. Their ages ranged from 19 to 35 . About $76 \%$ of the participants reported being in their 1 st or 2 nd year of university; $24 \%$ stated they were in their last year.

The participants were asked to report on their use of Bitcoin after watching the introductory video: $66 \%$ of respondents reported that they would use Bitcoin to buy goods and services; $14 \%$ of participants would use it for investing in crypto-currency; $6 \%$ reported they would use it to mine Bitcoin; and $20 \%$ of participants would use Bitcoin for all the reasons mentioned above.

The participants were also asked to state what things would encourage them to use Bitcoin: anonymity and no transaction fees were chosen by $66.5 \%$ of respondents; ease of use was chosen by $23 \%$ of respondents; $10.5 \%$ of respondents chose all three reasons mentioned above.

The participants described themselves as experienced and regular smartphone users: $67.7 \%$ had used smartphones for more than two years; $32.3 \%$ for more than three years; $81.41 \%$ spent at least two hours per day on smartphones; and $18.59 \%$ spent four hours or more per day.

The credit/debit card survey was completed by 33 undergraduate students, all of whom had no specific technical background in credit/debit cards, but had used them before. Of these, 9 participants reported to be female (27\%), and 73\% (24) to be male. Ages ranged from 19 to 35. 
Of the participants, 58\% claimed to be in their last year in university and $42 \%$ in their 1 st and 2nd year. $92 \%$ of the participants described themselves as regular smartphone users; $79 \%$ had used smartphones for more than two years and the rest for more than three years; $83 \%$ spent at least two hours per day; and 53\% spent more than four hours a day. The respondents were asked how many times they had used credit/debit cards online in the previous six months. About $63 \%$ of the respondents claimed to have used them two times a week; $18 \%$ reported that they had used them once every two weeks; and $9 \%$ reported that they used them once every month.

\subsection{Task results}

T1: In this task, all 22 participants were able to navigate the Blockchain.info site and successfully complete the task of creating a new Bitcoin wallet by providing an email address and a 10 character password. On the task sheets, all respondents successfully provided the correct steps. Most of the participants commented that the steps for configuring a new Bitcoin wallet were simple and straightforward.

T2: This task was about obtaining a Bitcoin receiving address and writing it down on the task sheet. The sheets showed that $72.7 \%$ (16) of the participants successfully managed to create a new Bitcoin address; 9 participants rated this task as difficult, and surprisingly 6 of the respondents failed to find the Bitcoin receiving address. The task sheet shows that those participants confused between the wallet ID and Bitcoin address. Later those (6) participants received some assistance from researcher and were successfully able to obtain the Bitcoin address required to proceed with the study.

T3: This task was about experiencing one of the security functions (auto logout) offered by the Bitcoin wallet. Almost half the participants (45.5\%) were unable to locate this important function; 10 participants were confused and had problems finding the auto logout function. Only $12(54.5 \%)$ of the 22 participants successfully got the right steps. 
T4: The fourth task was changing the login password: 95\% (21) of the participants successfully did the task and set a new login password for their Bitcoin wallet; only 1 participant was unable to change his login password and was confused by the second password offered by the wallet for extra security when sending Bitcoin or transacting.

T5: This task was about backing up the recovery phrase in the Bitcoin wallet in case of a lost password: $81.8 \%$ (18) of the participants were able to perform this task and set up the recovery phrase for their Bitcoin wallet; only 4 participants failed to set up a new back-up recovery phrase. The task sheets showed that 4 participants were not sure how to do the task and some confused backing up their wallet with authentication of passwords.

Table 2: Tasks Completion Rate

\begin{tabular}{llcll}
\hline Task & Completed (\%) & $\begin{array}{l}\text { Completed with } \\
\text { assistance }(\%)\end{array}$ & Failed (\%) & $\begin{array}{l}\text { Rated task as } \\
\text { difficult }(\%)\end{array}$ \\
\hline T1 & $100 \%$ & $0 \%$ & $0 \%$ & $8 \%$ \\
T2 & $73.9 \%$ & $26.1 \%$ & $26.1 \%$ & $41 \%$ \\
T3 & $53 \%$ & $0 \%$ & $47 \%$ & $50 \%$ \\
T4 & $95 \%$ & $0 \%$ & $5 \%$ & $5 \%$ \\
T5 & $82 \%$ & $0 \%$ & $19 \%$ & $28 \%$ \\
\hline
\end{tabular}

T6: This was not a core task that participants had to perform, it was optional. They were advised to go through the Bitcoin wallet and experience the security features offered along with the other useful functions, and comment on what things they most liked and disliked about the Bitcoin wallet. Some of the positive comments from 18 of the participants were:

A. Offers advanced authentication features, such as 2-step verification.

B. Balance can be shown in user local currency.

C. Can automatically be set to auto-generate a new wallet address after each transaction.

D. QR code can help pair the web wallet with a mobile device scanning and using it to share addresses to avoid having to type them. 
On the other hand, there were some negative comments that were considered very significant from the participants' perspectives:

E. 9 of the participants stated that the wallet ID, used to log in to the wallet, was a very long and unmemorable phrase. A wallet ID contains numbers, letters and dashes, is used only to log into the wallet, and should be kept private. The wallet ID can only be found in the welcome email.

F. 4 of the participants claimed that they faced some technical error messages when trying to send Bitcoin that were not understandable; for example, 'no free outputs to spend' was displayed when transactions were created without sufficient Bitcoins. Also, the participants mentioned that there was no available option to recover coins sent to the wrong address.

G. Participants reported that they couldn't buy Bitcoins by credit/debit card if the purchase amount was more than $£ 200$. They had to verify their identity before buying any Bitcoin valued over $£ 200$.

H. Participants also claimed that authentication processes were too long and complicated. To gain a preliminary thoughts on users' perceptions of Bitcoin usability and security, the data from task " 6 " is coded thematically, using standard qualitative analysis techniques and analyzed using a form of content analysis to extract the main themes from participants ${ }^{\text {ee }}$ comments. Based on these comments, we found that Security Authentication and usability efficiency perception are most frequently acknowledged by participants about the Bitcoin payment system. Participants expressed their appreciation of the 2 step verification method provided by the Bitcoin wallet. Implementing more than one step verifications increase users trust and reduce users' perception of risk. One of the participants said "2 step verification adds extra security when sign-in and you feel more protected - honestly, it's only an extra click" another participant stated, "It will be harder for anyone else trying to access my wallet". On 
the other hand, some participants claimed that authentication methods and long login IDs and special password characters require more work on the user's part, and it's another pain point. The following quotes represent participant views about this feature: "Not sure how someone can remember the login ID, every time needs to copy it from my email to get access". These complications of passwords and lengthy IDs may lead to frustration and reduce users' productivity. Bitcoin clients should consider using different login approaches to give the users freedom to choose the best approach that fits with his device and make him feel protected and productive.

The second theme found is efficiency attribute of usability, where efficiency is concerned about users' ability to accomplish tasks with less effort and less time. Users indicated that wallet allows users to see coins balance in their local currency. This helps the user to transact faster without the need to convert coins to their local currency using other application. Also, using QR code can minimize the time needed to type Bitcoin address or pair between web and mobile device. One of the participants stated, "QR code makes it easy for me to share my Bitcoin address, and quick to link my web wallet with my mobile device wallet”. Such features may help to increase users' performance efficiency and reduce efforts needed to accomplish tasks. This is a brief analysis of the participants' comments that help us to recognize some preliminary indications about users' perception of Bitcoin payment system.

\subsection{Survey results}

The descriptive statistics derived from the survey results are shown in Table 3. The MannWhitney U-test is a powerful test to compare outcomes between two independent groups and compare the number of times a score of one of the samples ranks higher than a score of the other sample regardless of the data normality. To find any difference between credit/debit card and Bitcoin perception and whether the scores between the two groups are statistically 
significant we applied two tailed probability to compare the scores of the two groups on the seven aspects examined. Table 4 shows the results of the Mann-Whitney U-test. The results indicate that, of the 7 areas examined, 5 show significant differences between credit/debit card and Bitcoin perceptions. The following sub-sections statistically explain the results for each area examined. The results of each sub-section are discussed based on the aspects of the systems examined.

Table 3: Descriptive Statistics

\begin{tabular}{|c|c|c|c|c|c|c|c|c|}
\hline & \multirow[t]{2}{*}{$\mathrm{N}$} & \multirow[t]{2}{*}{ Mean } & \multirow[t]{2}{*}{ Std. Deviation } & \multirow[t]{2}{*}{ Minimum } & \multirow[t]{2}{*}{ Maximum } & \multicolumn{3}{|c|}{ Percentiles } \\
\hline & & & & & & $25^{\text {th }}$ & 50th (Median) & 75th \\
\hline Learnability & 55 & 3.7909 & .95108 & 2.000 & 5.000 & 3.000 & 4.000 & 4.000 \\
\hline Efficiency & 55 & 3.7091 & 95593 & 2.000 & 5.000 & 3.000 & 4.000 & 4.000 \\
\hline Memorability & 55 & 3.6727 & 1.00101 & 2.000 & 5.000 & 3.000 & 4.000 & 4.000 \\
\hline Error & 55 & 3.6818 & .53023 & 2.000 & 5.000 & 3.500 & 4.000 & 4.000 \\
\hline Help & 55 & 3.3818 & .78742 & 2.000 & 5.000 & 3.000 & 3.000 & 4.000 \\
\hline Security & 55 & 3.2364 & .92223 & 1.000 & 5.000 & 3.000 & 3.000 & 4.000 \\
\hline Satisfaction & 55 & 3.6182 & .90760 & 2.000 & 5.000 & 3.000 & 4.000 & 4.000 \\
\hline
\end{tabular}

Table 4: Mann Whitney Test

\begin{tabular}{lccccccc}
\hline & Learnability & Efficiency & Memorability & Error & Help & Security & Satisfaction \\
\hline $\begin{array}{l}\text { Mann- } \\
\text { Whitney U }\end{array}$ & 172.500 & 153.000 & 259.500 & 358.500 & 241.000 & 230.000 & 117.500 \\
$\begin{array}{l}\text { Wilcoxon } \\
\text { W }\end{array}$ & 425.500 & 406.000 & 512.500 & 611.500 & 494.000 & 483.000 & 370.500 \\
$\begin{array}{l}\text { Z } \\
\text { Asymp. Sig. }\end{array}$ & -3.447 & -4.009 & -1.873 & -.083 & -2.186 & -2.410 & -4.358 \\
$\begin{array}{l}(2-\text { tailed) } \\
\begin{array}{l}\text { Effect size } \\
\text { (r) }\end{array}\end{array}$ & .001 & .000 & .061 & .934 & .029 & .016 & .000 \\
\hline
\end{tabular}

\subsubsection{Learnability}

Based on the descriptive statistical results shown in Table 3, credit/debit card users' perceptions $($ median $=4.00$; mean rank $=33.77)$ scored higher on learnability than Bitcoin 
$($ median $=3.00 ;$ mean rank $=19.34) . \mathrm{U}=$ Mann-Whitney test statistic $=172.500 ; \mathrm{W}=$ Wilcoxon $\mathrm{W}$ statistic $=425.500 ; \mathrm{z}=\mathrm{U}$ transformed into a normally distributed $\mathrm{z}=-3.447 ; \mathrm{p}<0.001$ as shown in Table 5. The test results show a significant difference between credit/debit card and Bitcoin in terms of learnability. The difference between the groups is medium $(r=-0.46)$. Therefore hypothesis $\mathrm{H} 1$ is rejected.

Table 5: Analysis of learnability

\begin{tabular}{ll}
\hline & Learnability \\
\hline Mann-Whitney U & 172.500 \\
Wilcoxon W & 425.500 \\
Z & -3.447 \\
Asymp. Sig. (2-tailed) & .001 \\
\hline
\end{tabular}

\subsubsection{Efficiency}

Descriptive statistics show that credit/debit card (median $=4.00$; mean rank $=34.36)$ scored higher on efficiency than Bitcoin (median $=3.00$; mean rank $=18.45$ ) as shown in Table $3 . \mathrm{U}$ $=$ Mann-Whitney test statistic $=153 ; \mathrm{W}=$ Wilcoxon $\mathrm{W}$ statistic $=406 ; \mathrm{z}=\mathrm{U}$ transformed into a normally distributed $\mathrm{z}=-4.009 ; \mathrm{p}=0.000<0.001$ as shown in Table 6 . The test results show a significant difference between credit/debit card and Bitcoin in terms of efficiency. The difference between the groups is quite large $(\mathrm{r}=-0.54)$. Therefore hypothesis $\mathrm{H} 2$ is rejected.

Table 6: Analysis of efficiency

\begin{tabular}{ll}
\hline & Efficiency \\
\hline Mann-Whitney U & 153.000 \\
Wilcoxon W & 406.000 \\
Z & -4.009 \\
Asymp. Sig. (2-tailed) & .000 \\
\hline
\end{tabular}

\subsubsection{Memorability}

Based on the Mann-Whitney U test results the mean rank for memorability is not statistically significantly different between credit/debit card and Bitcoin. $\mathrm{U}=$ Mann-Whitney test statistic 
$=259.500 ; \mathrm{W}=$ Wilcoxon $\mathrm{W}$ statistic $=512.500 ; \mathrm{z}=\mathrm{U}$ transformed into a normally distributed $\mathrm{z}=-1.873 ; \mathrm{p}=0.061$. Even though there are no significant differences in the memorability aspect, credit/debit card $($ median $=4.00$; mean rank $=31.14)$ scored higher than Bitcoin ( median $=3$; mean rank $=23.30)$ as shown in Table 7 . This indicates that the participants found transacting with credit/debit cards quite easy to remember. The difference between the groups is small $(\mathrm{r}=-.025)$. Therefore hypothesis H3 is accepted.

Table 7: Analysis of memorability

\begin{tabular}{ll}
\hline & Memorability \\
\hline Mann-Whitney U & 259.500 \\
Wilcoxon W & 512.500 \\
Z & -1.873 \\
Asymp. Sig. (2-tailed) & .061 \\
\hline
\end{tabular}

\subsubsection{Error \& Recoverability}

Based on the Mann-Whitney U test results, the mean rank of error and recoverability is not statistically significantly different between the examined systems, $U=358.500, z=-0.083, p$ $=.934$ as shown in Table 8 . However, both systems achieved high median scores for error $\&$ recoverability $($ median $=4.0 \& 3.50)$. The difference between the groups is very small $(\mathrm{r}=-$ .011). This reveals that the participants found both systems equally easy regarding errors \& recoverability. Therefore hypothesis $\mathrm{H} 4$ is accepted.

Table 8: Analysis of Errors

\begin{tabular}{ll}
\hline & Errors \& Recoverability \\
\hline Mann-Whitney U & 358.500 \\
Wilcoxon W & 611.500 \\
Z & -.083 \\
Asymp. Sig. (2-tailed) & .934 \\
\hline
\end{tabular}

\subsubsection{Help}

Based on the descriptive statistics results in Table 3, credit/debit card users' perceptions $($ median $=4.00 ;$ mean rank $=31.70)$ scored higher on help than Bitcoin (median $=3.00 ;$ mean 
rank $=22.45) . \mathrm{U}=$ Mann-Whitney test statistic $=241.000 ; \mathrm{W}=$ Wilcoxon $\mathrm{W}$ statistic $=$ 494.000; $\mathrm{z}=\mathrm{U}$ transformed into a normally distributed $\mathrm{z}=-2.186 ; \mathrm{p}<0.029$ as shown in Table 9. The test results reveal a significant difference between credit/debit card and Bitcoin in terms of help support. The difference between the groups is medium $(\mathrm{r}=-0.3)$. Therefore hypothesis $\mathrm{H} 5$ is rejected.

Table 9: Analysis of Help

\begin{tabular}{ll}
\hline & Help \\
\hline Mann-Whitney U & 241.000 \\
Wilcoxon W & 494.000 \\
Z & -2.186 \\
Asymp. Sig. (2-tailed) & .029 \\
\hline
\end{tabular}

\subsubsection{Security}

The Mann-Whitney U-test shows a significant difference between credit/debit card participants and the Bitcoin group in terms of security perception. Mann-Whitney test statistic $=230.000 ; \mathrm{W}=$ Wilcoxon $\mathrm{W}$ statistic $=483.000 ; \mathrm{z}=\mathrm{U}$ transformed into a normally distributed $\mathrm{z}=-2.410 ; \mathrm{p}<0.016$ as shown in Table 10. Credit/debit card users' perceptions (median $=$ 4.00; mean rank $=32.03)$ scored higher on security than Bitcoin $($ median $=3.00 ;$ mean rank $=$ 21.95). The difference between the groups is moderate $(\mathrm{r}=-.32)$. Therefore hypothesis H6 is rejected.

Table 10: Analysis of Security

\begin{tabular}{ll}
\hline & Security \\
\hline Mann-Whitney U & 230.000 \\
Wilcoxon W & 483.000 \\
Z & -2.410 \\
Asymp. Sig. (2-tailed) & .016 \\
\hline
\end{tabular}

\subsubsection{Satisfaction}

Based on the Mann-Whitney U-test results, the mean rank of satisfaction is statistically significantly different between credit/debit card and Bitcoin. $\mathrm{U}=$ Mann-Whitney test statistic 
$=117.500 ; \mathrm{W}=\mathrm{Wilcoxon} \mathrm{W}$ statistic $=370.500 ; \mathrm{z}=\mathrm{U}$ transformed into a normally distributed $\mathrm{z}=-4.358 ; \mathrm{p}=0.000<0.001$. The median reveals that credit/debit card (median $=4.00 ;$ mean rank $=35.44)$ scored higher than Bitcoin (median $=3$; mean rank $=16.84)$ as shown in Table 11. This indicates that the participants were more satisfied with credit/debit card than Bitcoin. The difference between the groups is large $(\mathrm{r}=-.58)$. Therefore hypothesis $\mathrm{H} 7$ is rejected.

Table 11: Analysis of Satisfaction

\begin{tabular}{ll}
\hline & Satisfaction \\
\hline Mann-Whitney U & 117.500 \\
Wilcoxon W & 370.500 \\
Z & -4.358 \\
Asymp. Sig. (2-tailed) & .000 \\
\hline
\end{tabular}

\section{Discussion}

This study investigates the perceptual differences between Bitcoin's anonymous system and credit/debit cards as a non-anonymous payment system among undergraduate students in terms of usability and security. The goal of this paper is to answer the research question given in Section 1 in order to understand how users interact with anonymous Bitcoin compared with the currently most used payment system (credit/debit cards), with an emphasis on usability and security. This is a first user study, which focuses on user perception of Bitcoin usability and security trade-off in comparison with other payment systems. As we noted earlier, this study was performed at the time when the Bitcoin was still primarily used as a digital crypto-currency and not as an investment tool.

The main aims of setting the tasks was to encourage the participants to explore the capabilities of an anonymous payment system, improve the participants' familiarity with Bitcoin, and increase our understanding of their perceptions of the usability and security aspects. Giving the respondents tasks helps to reduce the potential ambiguity of answers to survey questions. 
The survey results indicate that 5 of the tested hypotheses, H1, H2, H5, H6 and H7, are rejected. The analyzed data reveal significant differences in users' perceptions of credit/debit cards and Bitcoin for learnability, efficiency, help, security and satisfaction, as explained in Section 5.3. However, no significant difference is shown relating to the usability aspects of memorability and error. Comparing the usability attributes of both systems shows that the respondents perceived the usability of credit/debit cards higher than Bitcoin. The participants had negative perceptions of Bitcoin's security that been affected by the low rate of usability.

The following subsections discuss the result of each aspect individually and recommend a guideline for each. We also explore the relevant lessons for the application of secure cryptocurrencies in the context of e-government services.

\subsection{Learnability}

Learnability is how easy the system is to learn and use. This attribute is essential for novice users. A key finding revealed by the analysis of participants' experiences, is that the ease of learnability criterion was an issue for Bitcoin. The $\mathrm{T} 2$ results show that $26.1 \%$ of participants (see Table 2) were unable to find the Bitcoin receiving address, which is an essential piece of information needed when conducting any transaction. This task was rated by $41 \%$ of the participants as difficult. By evaluating the Bitcoin client we found that the receiving address can be located under the "Request" tab, which could easily be confused by users for the other tab "Received Coins". The "Received Coins" tab only shows the history of the Bitcoin received. There was a popular misconception among novice users that a Bitcoin address looks like an email address, which makes it hard for users to find the receiving address first try. T3 was rated as difficult by $50 \%$ of participants who were unsuccessful in locating and setting up one of the available functions; $47 \%$ of participants failed to accomplish this task. We assume that the failure to locate the "Auto Logout" function was due to the function location. The "Auto Logout" function should be located in the "Security Settings" tab but is located under 
the "User Preferences" tab. It is obvious that novice users were not able to accomplish basic tasks the first time they used Bitcoin. Learnability is a major usability aspect with a great influence on how users rate other usability attributes.

The survey results reveal that credit/debit cards have higher learnability than Bitcoin based on user experience. This indicates that users took more time to learn to use the Bitcoin wallet and were not able to use it effectively. However, using credit/debit cards for online purchases requires users to fill in lengthy forms with personal data and card details, and therefore cannot be considered as an easy option. The results reveal that users perceive it differently in term of being easy to learn, even though it is not an appropriate method. It could be that users have become familiar with filling in these types of payment details over the years, or usability experts overestimate the complexity of credit/debit card payments.

The survey results on usability emphasize the importance of learnability to Bitcoin users.

In order to develop crypto-currency based e-government systems that are likely to become popular, designers must give high priority to learnability. Learnability is an essential usability attribute that has a great influence on novice users' perceptions. Improving system learnability is likely to improve users' perceptions of other usability aspects.

In light of the above, we recommend that Bitcoin developers focus on the essential functions that are used most by users, such as "Bitcoin Address", "Receive" and "Send". Developers should make the most important functions accessible from every section of the Bitcoin client, make them specific and avoid being ambiguous. Everyday familiar short words should be used to identify these functions. This would help simplify user interaction with the Bitcoin client and help users adjust to it quickly. The system should be consistent and logical to help Bitcoin users recognize repeating patterns and use the Bitcoin client intuitively. Developers should focus on reducing prioritization and organization functions to simplify user interaction with the Bitcoin client. We propose that developers reduce the number of actions or clicks needed to 
accomplish essential tasks, in order to decrease the cognitive load on users. Designers should also present a balanced set of options to the user. Fewer relevant choices would help users make the right decision and improve the overall learnability. Prioritization of these important functions, based on their significance to the user, would help users pay attention to them. Also, appropriate categorization and grouping related functions in tabs would reduce the chance of users being confused by the vast number of options. Adding standard interactive graphical elements to Bitcoin clients would help users learn quickly from previous experience and make them feel more comfortable. Designers could also use icons that are more comfortable for users, and allow them to modify these icons by choosing from sets of alternatives. Using a graphical icon is meaningful to users from different backgrounds and can be perceived faster than text.

\subsection{Efficiency}

Efficiency is another issue for the Bitcoin system, based on the participants' comments on the tasks. Participants commented negatively on the accuracy and speed of performing tasks as stated in comments $\mathrm{E}$ and $\mathrm{H}$ in Section 5.2. Rating tasks as difficult is an indication that the participants expended effort accomplishing them, as shown in Table 2.

The survey results show that credit/debit cards have a higher degree of efficiency than Bitcoin. Bitcoin as a payment system was rated by respondents as not efficient compared to credit/debit cards. Based on Cohen's classification, the difference between the two groups is large enough to be significant. Users perceive Bitcoin as less efficient than credit/debit cards despite the ability of Bitcoin systems to accept micropayments, without transaction fees. It is possible that users consider micropayments as unimportant features for them. Small payments of less than $£ 1$ are rare nowadays. Transaction speed is another potential issue for Bitcoin Blockchain; for example if you purchase a cup of coffee using Bitcoin, you may wait for minutes or hours for your transaction to be approved in the Blockchain by miners. Users' lack 
of background knowledge of Bitcoin may also influence their perception. Clearly there is a potential usability issue in respect to efficiency. While it may sound obvious, it is important to underline that providing the experience of efficiency is key for the development of successful crypto-currency based e-government services. Our results show that lack of efficiency can undermine very much the perception of usability and consequently may limit considerably the take-up of the service.

Based on the results above, we recommend that designers consider applying two different designs to the Bitcoin client. They should consider implementing two different modes designed to fit novice and expert users, and give them the freedom to choose and switch between them as required. As we know that the two sets of users have different experiences and strategies for using the same application, this design would increase efficiency for both novice and expert users. It would provide users with alternative methods of accomplishing the same activity efficiently and help them switch between the designs based on technology experience and preference. Giving the users the option to choose between two designs would allow them to accomplish tasks faster, as each design would be directed to suit each set of users. On the other hand, the volatility in transaction time makes it challenging for Bitcoin to be applied as a payment system, despite the lower fees. What we currently see, is that Bitcoin has always been slow in comparison to a credit card transaction, and senders and receivers are uncomfortable if they have to wait more than 10 minutes, on average, for the Bitcoin network to propagate the payment. Bitcoin's developer community has to find a solution to this problem in order to enable users to transact quickly, with lower fees. Right now, there are some promising projects trying to solve the transaction speed issue for Bitcoin and increase the number of transactions per second to ensure the highest efficiency.

\subsection{Memorability}


The statistical results show no significant difference between users' perceptions in terms of memorability. Users perceived both systems equally. However, on further investigation and comparing the difference between the two groups using Cohen's classification, credit/debit cards scored 25\% higher than Bitcoin, which is a small difference. This means that credit/debit cards are perceived to have greater memorability, even though the difference is small. It is possible that when a system is easy to learn, users are more willing to relearn how to use it, and therefore memorability may not be as important as it is for credit/debit cards. Bitcoin has a steeper learning curve, and is considered by users as difficult to learn, therefore learning such a system requires a significant amount of time. For this reason, designers must consider memorability as an important usability aspect when designing crypto-currency based egovernment systems and services.

Generally, Bitcoin addresses are too long and extremely difficult to remember for most users. Some Bitcoin clients implement QR codes to allow users sharing addresses to avoid having to type them. However, QR codes are not an efficient solution due to the vulnerabilities inherent in the standard, and the ease of social manipulation attacks. In our opinion, Bitcoin developers should introduce an appropriate system to translate the Bitcoin hash address into a visual representation, similar to the name system of DNS, and vice versa. This would help make Bitcoin addresses more human and easier to remember. Bitcoin developers should also address the issue of long login IDs, which are not easy to remember. Developers should make these login IDs slightly personalized and therefore easier to recall. Bitcoin clients should have more graphic interfaces, for better memorability, because humans are better at recognition than recall.

\subsection{Error \& Recoverability}

With regard to the error and recoverability information aspect of usability, the participants found some of the error messages too technical to understand, as stated in comment F in Section 
5.2. Also, the participants showed some concern about sending Bitcoin to the wrong address, in which case the transaction can't be recovered.

However, the survey results reveal no significant difference between Bitcoin and credit/debit card users' perceptions of error and recoverability. Comparing the difference in effect of the two groups shows a small difference, with credit/debit cards having a lower error rate (by $11 \%$ ) and higher recoverability than Bitcoin. A possible explanation is that Bitcoin users can't reverse or cancel transactions, whereas credit/debit card users can call their banks and reverse any transactions. Moreover, inadequate user knowledge of Bitcoin and Blockchain, which are not mature technologies, may influence users' perceptions.

Novel e-government services relying on crypto-currencies must make sure that the error and recoverability information provision to users is adequate and technical terms used in such information are sufficiently easy to understand and operate with.

In order to reduce the possibility of errors due to the lack of an undo feature in the Bitcoin client for the transfer of coins to other party, Bitcoin developers should implement a system to allow users to roll transactions back, for a fixed fee. Also, it is possible for developers to put an optional feature in Bitcoin clients to allow users to lock any transfer of a large amount for one day and send a notification to the receiver to confirm the Bitcoin address. We recommend that any Bitcoin client should have smart error prevention features, such as user reminders about the amount of coin sent (e.g., too small or too big) before processing the transaction. This could help effectively minimize the occurrence and consequences of errors. Regarding the technical error messages that users encounters, developers should avoid using technical terms and codes. These error messages should be clear, easy to understand and concise. The developer should implement a way of taking the user to a screen that explains why they received the error message and tell them what to do next. In general, users need a description of what has happened to work out how to fix the error. Error messages should be expressed in 
plain language that suggests what further action users need to take to overcome the error and suggest a solution.

\subsection{Help}

Help is a significant usability attribute, and the help available should be relevant, understandable, searchable and useful in a specified context of use. The results show that users perceived credit/debit cards better than Bitcoin in terms of help. A potential explanation is that Bitcoin clients use highly technical language when providing help, and there is a lack of resources which users can turn to for help. Some users said that help messages were not understandable. In general, when a system is easy to learn and easy to use, users put minimal reliance on help and documentation. Bitcoin interface designers should keep the instructions easy to identify, and they should appear in a consistent location whenever they are needed. Bitcoin clients should include a help section with all the relevant answers expected by users when they encounter problems. The help section should have the capability to increase the problem solving ability of users and contain guidance and advice on most expected issues. Developers should make information that easy to search, focused on the user's task, list concrete steps to be carried out, and not be too large.

As with the cases of error and recoverability information, it is important that any new egovernment service that may use crypto-currencies provides adequate and technically easy to understand help information to the users in order to achieve high take up.

\subsection{Satisfaction}

Some of the assigned tasks were challenging for many users, and many failed to do them, for example finding the receiving address and setting the auto logout and backup. Some participants expressed discomfort in using the Bitcoin wallet due to its complexity and the lack of knowledge of novice users. 
In term of user satisfaction, in line with the task experience reports, the survey results show that the credit/debit card respondents had high levels of comfort compared to the Bitcoin users, who were unsatisfied with their Bitcoin experience. This could be explained by Bitcoin users being influenced in negative ways by the usability limitations of the system.

The findings imply that users' satisfaction with Bitcoin is significantly influenced by their perceptions of usability. Missing important functions and features in Bitcoin clients, such as the lack of an undo option, along with long transaction processing times cause lower user satisfaction. In general, the complexity of Bitcoin, the absence of legal authority, and having no control over transactions have a great influence on users' overall levels of satisfaction. To increase user satisfaction, we recommend that developers put more effort into user requirements, and apply features that make users feel in control when using the system. User satisfaction would be perceived as better if developers make the operational tasks that users have to perform easier, speed up transaction processing time, and simplify the features of the Bitcoin system.

The satisfaction results highlight the importance of delivering good usability in order to achieve good customer satisfaction with any new e-government service relying on cryptocurrencies. While this is generally true, in the context of introduction of new services relying on novel and sophisticated computational technology, this is particularly important.

\subsection{Security}

With regard to the security aspect, the participants had a negative experience with the Bitcoin, which is reflected in some of their comments about the authentication methods. The participants reported that logging in to the wallet was difficult because of the long ID used. Also, the time and effort needed to set up all the security authentication features for the wallet were problematic, as stated in comment $\mathrm{H}$ in Section 5.2.

On the other hand, the participants gave some positive comments about features they found useful such as advanced authentication features, 2-step verification, balance shown in user local 
currency, the ability to auto-generate a new wallet transaction address after each transaction, and the option to pair a web wallet with a mobile device by scanning a QR code.

The survey results reveal that the respondents perceived Bitcoin security differently from the way it is actually realized. Despite the fact that credit/debit card payments are less secure and have less anonymity, users perceived them as more secure than Bitcoin. A possible explanation is that users do not find anonymity important or are unaware of the actual situation.

Another possible reason is that the usability limitations of Bitcoin have a negative influence on how users' perceive security. Also, the knowledge or skill level of the respondents plays a major role in user security perceptions. This means that many users don't have enough knowledge about Bitcoin's benefits, or are just following the trend of using Bitcoin. According to the results, many users were concerned about Bitcoin's legal status and customer protection, both of which may indirectly influence their security perceptions. Some of the security features highlighted by the tasks may have had negative impacts on the users' perceptions, such as the length of the authentication process and login ID.

We suggest that Bitcoin developers focus on providing various security levels in Bitcoin clients, for example transfers between the user's own Bitcoin wallets should not be treated the same as transfer to a trader. Security alerts and notifications should be more clear and concise, and users should be notified when confidential settings are accessed or when there is any change. Important security settings should be categorized and grouped under one tab and guidance provided for users on how to use them. Also, we propose that developers help users switch between two privacy preferences, anonymous and non-anonymous, to give them freedom and feeling of control over transactions. Designers should make sure that security settings are easy to set up and clearly visible to the end user. Bitcoin payment systems, as with any systems, have some security and privacy vulnerabilities. Developers should acknowledge 
these vulnerabilities to end users, so they can protect themselves by applying the security and privacy features of the application correctly and effectively.

These results highlight the importance of usability and legal clarity in relation with any crypto-currency that might be used to support novel e-government services. The lack of appropriate delivery of these features can undermine the appreciation of security or other advanced technical features of the service by its users. This in turn may considerably reduce the willingness to take-up and use the service.

\section{LIMITATIONS}

The small sample size is one limitation, due to the nature of the study and the methodology used. This small sample size limits the generalizability of the study. Another limitation is that the researchers did not focus on the social influences or social interactions that may influence user perceptions of usability and security. Some respondents may have socio-culturally biased interpretation of some questions in the questionnaire. However, all questions were thoroughly pre-tested and improved in a pilot study before being given to the participants.

\section{CONCLUSION \& RECOMMENDATIONS}

This comparison between credit/debit cards and Bitcoin users' perceptions in terms of usability and security shows significant differences in five aspects: learnability, efficiency, help, security and satisfaction. The study shows that credit/debit cards and Bitcoin users perceive memorability and errors of usability attributes in almost the same way. The results of the hypothesis testing and statistical interpretation described in the previous sections, show that credit/debit cards have the best overall usability perception, which has a positive influence on 
their security perception. On the other hand, Bitcoin has the poorer usability perception which has a negative influence on how users perceive its security.

Therefore, our results show that usability and security have a close relationship. In other words, users' perceptions of usability and security positively influence each other. The findings suggest that perceived security, as measured by the questionnaires, is affected by the users' overall usability perception.

The results revealed that Bitcoin, as a crypto-currency, is still a major challenge for many users. We conclude that Bitcoin cryptocurrency payment system is still in its infancy and requires user education and a new way of thinking. It is recommended that users' mental models are developed in order to deepen developer understanding of anonymous cryptocurrencies technology and improve user-centred design. The results indicated that users perceive some usability characteristics of crypt-currency payment system higher than others and some characteristics much less. From our point of view, it is significant to understand what usability aspects of anonymous payment systems have most direct influence on user perception and what characteristics are more essential for user acceptance.

Also, it is important to narrow the gap between Bitcoin Blockchain technology and user expectations, in order to have better user usability and build trust. Insufficient government regulation and Bitcoin application standards are among many reasons that affect users' acceptance of Bitcoin as an anonymous payment system. Bitcoin Blockchain technology still not mature enough, not systematically studied and risks surrounding it still unknown. A common Blockchain platform, application standards, and application programming interfacing are required to improve user perception and interaction.

Our analysis of the results provides useful guidelines for the development of future egovernment services that rely on the use of anonymous crypto-currencies and related technologies. In particular, our key recommendation is to invest in the improvement of the 
usability of the service and delivery of usability features at a high level. Without this potential users will not appreciate sufficiently the security benefits of such new e-government services and the likely take-up and user satisfaction will be limited.

Our study points to the need for further investigation to get a better understanding of users and address user usability and security issues and the trade-off between these. A comparison between expert and novice users is recommended in order to investigate how expert users perceive usability and security in comparison to novice users.

\section{REFERENCES}

Abran, A., Khelifi, A., \& Suryn, W. (2003). Usability meanings and interpretations. Software Quality Journal, 11(4), 323-336.

Alberto, P. (2010). User-centric mobile services: context provisioning and user profiling. 11th Annual International Conference on Digital Government Research (Dg.o 2010), 122-130. http://doi.org/10.5326/JAAHA-MS-5690

Androulaki, E., Karame, G. O., Roeschlin, M., Scherer, T., \& Capkun, S. (2013). Evaluating User Privacy in Bitcoin. Financial Cryptography and Data Security, 34-51. http://doi.org/10.1007/978-3-642-39884-1_4

Athey, S., Parashkevov, I., Sarukkai, V., \& Xia, J. (2016). Bitcoin Pricing, Adoption, and Usage: Theory and Evidence. Stanford University Graduate School of Business Research Paper, 16(42), 70. Retrieved from https://papers.ssrn.com/sol3/papers.cfm?abstract_id=2826674

Bamert, T., Decker, C., Elsen, L., Wattenhofer, R., \& Welten, S. (2013). Have a snack, pay with Bitcoins. 13th IEEE International Conference on Peer-to-Peer Computing, IEEE P2P 2013 - Proceedings, (c). http://doi.org/10.1109/P2P.2013.6688717

Barber, S., Boyen, X., Shi, E., \& Uzun, E. (2012). Bitter to better - How to make bitcoin a better currency. Lecture Notes in Computer Science (Including Subseries Lecture Notes in Artificial Intelligence and Lecture Notes in Bioinformatics), 7397 LNCS, 399-414. http://doi.org/10.1007/978-3-642-32946-3_29

Baur, A. W., Bühler, J., Bick, M., \& Bonorden, C. S. (2015). Cryptocurrencies as a disruption? empirical findings on user adoption and future potential of Bitcoin and Co. Lecture Notes in Computer Science (Including Subseries Lecture Notes in Artificial Intelligence and Lecture Notes in Bioinformatics), 9373, 63-80. http://doi.org/10.1007/978-3-319-25013-7_6

Ben-Sasson, E., Chiesa, A., Garman, C., Green, M., Miers, I., Tromer, E., \& Virza, M. 
(2014). Zerocash: Decentralized anonymous payments from bitcoin. Proceedings - IEEE Symposium on Security and Privacy, 459-474. http://doi.org/10.1109/SP.2014.36

Bitcoin.org. (2018). Bitcoin. Retrieved August 11, 2018, from https://bitcoin.org/en/, 2018.

Böhme, R., Christin, N., Edelman, B., \& Moore, T. (2015). Bitcoin: Economics, Technology, and Governance. Source: The Journal of Economic Perspectives Journal of Economie Perspectives-Volume, 29(2—Spring), 213-238. http://doi.org/10.1257/jep.29.2.213

Bohr, J., \& Bashir, M. (2014). Who Uses Bitcoin? An exploration of the Bitcoin community. 2014 12th Annual Conference on Privacy, Security and Trust, PST 2014, 94-101. http://doi.org/10.1109/PST.2014.6890928

Bonneau, J., Miller, A., Clark, J., Narayanan, A., Kroll, J. A., \& Felten, E. W. (2015). SoK: Research perspectives and challenges for bitcoin and cryptocurrencies. Proceedings IEEE Symposium on Security and Privacy, 2015-July, 104-121. http://doi.org/10.1109/SP.2015.14

Boucher, P., Nascimento, S., \& Kritikos, M. (2017). How Blockchain Technology Could Change Our Lives. European Parliamentary Research Service, 24. http://doi.org/10.2861/926645

Braz, C., Seffah, A., \& Raihi, D. M. (2007). Designing a Trade-Off Between Usability and Security: A Metrics Based-Model. Lecture Notes in Computer Science, 4663, 114-126. http://doi.org/10.1007/978-3-540-74800-7_9

Brito, J., \& Castillo, A. (2013). Bitcoin: A Primer for Policymakers. Mercatus Center: Geroge Mason University., 29(4), 3-12. http://doi.org/10.1017/CBO9781107415324.004

BusinessInsider. (2018). Cryptocurrency price.

Candiwan, Beninda, M. Y. D., \& Priyadi, Y. (2016). Analysis of Information Security Audit Using ISO 27001:2013 \& ISO 27002:2013 at IT Division - X Company, In Bandung, Indonesia. International Journal of Basic and Applied Science, 4(4), 77-88. http://doi.org/10.13140/RG.2.1.1483.3044

Choi, J. (Jong U., Ae Chun, S., \& Cho, J.-W. (2014). Smart SecureGov. Proceedings of the 15th Annual International Conference on Digital Government Research - Dg.o '14, 9199. http://doi.org/10.1145/2612733.2612756

Churchill, E. F. (2015). Why should we care about Bitcoin? Interactions, 22(5), 20-21. http://doi.org/10.1145/2810199

Cohen J. (1992). A Power Primer. Psychological Bulletin, 112(1). http://doi.org/10.1038/141613a0

Coutu, O. (2014). Privacy in Bitcoin through decentralized mixers.

de Jong, M., \& Lentz, L. (2006). Scenario evaluation of municipal Web sites: Development and use of an expert-focused evaluation tool. Government Information Quarterly, 23, 191-206. http://doi.org/10.1016/j.giq.2005.11.007

Dzida, W., Herda, S., \& Itzfeldt, W. D. (1978). User-Perceived Quality of Interactive Systems. IEEE Transactions on Software Engineering, SE-4(4), 270-276. http://doi.org/10.1109/TSE.1978.231511

Eskandari, S. (2015). Real-world Deployability and Usability of Bitcoin, (October).

Eskandari, S., Clark, J., Barrera, D., \& Stobert, E. (2015). A first look at the usability of bitcoin key management, (February). http://doi.org/10.14722/usec.2015.23015

Gao, X., Clark, G. D., \& Lindqvist, J. (2015). Of Two Minds, Multiple Addresses, and One History: Characterizing Opinions, Knowledge, and Perceptions of Bitcoin Across Groups, 1-21. Retrieved from http://arxiv.org/abs/1503.02377

Garcia, D., Tessone, C. J., Mavrodiev, P., \& Perony, N. (2014). The digital traces of bubbles: feedback cycles between socio-economic signals in the Bitcoin economy. 
http://doi.org/10.1098/?rsif.2014.0623

Gibbons, J. D., \& 1938-. (1976). Nonparametric methods for quantitative analysis. Holt, Rinehart and Winston.

Goldfeder, S., Bonneau, J., Felten, E. W., Kroll, J. a, \& Narayanan, A. (2014). Securing Bitcoin wallets via threshold signatures. Retrieved from https://freedom-totinker.com/blog/stevenag/new-research-better-wallet-security-for-bitcoin/

Hern, A. (2013). (2013). Missing: hard drive containing Bitcoins worth $£ 4 \mathrm{~m}$ in Newport landfill site. Retrieved from www.theguardian.com/technology/2013/nov/27/hard-dr

Herrera-joancomart, J. (2015). Research and Challenges on Bitcoin Anonymity, (September), 1-14. http://doi.org/10.1007/978-3-319-17016-9

Hornbæk, K., \& Law, E. L.-C. (2007). Meta-analysis of correlations among usability measures. Proceedings of the SIGCHI Conference on Human Factors in Computing Systems - CHI '07, 617. http://doi.org/10.1145/1240624.1240722

Johnson, E. M., \& Willey, N. D. (2011). Usability Failures and Healthcare Data Hemorrhages. IEEE Security \& Privacy Magazine, (March/April), 35-42. http://doi.org/10.1109/MSP.2010.196

Jose, S. (2016). Exploring Motivations among Bitcoin, 2872-2878. http://doi.org/10.1145/2851581.2892500\}

Kaye, J., Vertesi, J., Ferreira, J., Brown, B., \& Perry, M. (2014). \#CHImoney: financial interactions, digital cash, capital exchange and mobile money. Proceedings of the Extended Abstracts of the 32nd Annual ACM Conference on Human Factors in Computing Systems - CHI EA '14, 111-114. http://doi.org/10.1145/2559206.2559221

Koshy, P., Koshy, D., \& McDaniel, P. (2014). An analysis of anonymity in bitcoin using P2P network traffic. Lecture Notes in Computer Science (Including Subseries Lecture Notes in Artificial Intelligence and Lecture Notes in Bioinformatics), 8437, 469-485. http://doi.org/10.1007/978-3-662-45472-5_30

Kotamraju, N. P., \& van der Geest, T. M. (2012). The tension between user-centred design and e-government services. Behaviour \& Information Technology, 31(3), 261-273. http://doi.org/10.1080/0144929X.2011.563797

Krombholz, K., Judmayer, A., Gusenbauer, M., \& Weippl, E. (2016). The Other Side of the Coin: User Experiences with Bitcoin Security and Privacy. Financial Cryptography and Data Security 2016. Retrieved from http://fc16.ifca.ai/preproceedings/33_Krombholz.pdf

Lee, S., \& Koubek, R. J. (2010). Understanding user preferences based on usability and aesthetics before and after actual use. Interacting with Computers, 22(6), 530-543. http://doi.org/10.1016/j.intcom.2010.05.002

Leon, P. G., Ur, B., Balebako, R., Cranor, L. F., Shay, R., \& Wang, Y. (2011). Why Johnny Can' t Opt Out : A Usability Evaluation of Tools to Limit Online Behavioral Advertising Why Johnny Can' t Opt Out : A Usability Evaluation of Tools to Limit Online Behavioral Advertising. Proceedings of the SIGCHI Conference on Human Factors in Computing Systems, 589-598.

Lesemann, E., Woletz, N., \& Koerber, S. (2007). Combining methods to evaluate mobile usability. Proceedings of the 9th International Conference on Human Computer Interaction with Mobile Devices and Services - MobileHCI '07, 444-447. http://doi.org/10.1145/1377999.1378051

Luther, W., \& Olson, J. (2013). Bitcoin is Memory. Available at SSRN, 18. http://doi.org/10.2139/ssrn.2275730

Mainelli, M., \& Smith, M. (2015). Sharing ledgers for sharing economies: an exploration of mutual distributed ledgers (aka blockchain technology). The Journal of Financial 
Perspectives, 3(3 Winter), 38-69. Retrieved from https://www.gfsi.ey.com/the-journalx.php?pid=18\&id $=110$

Maurer, B., Nelms, T. C., \& Swartz, L. (2013). "When perhaps the real problem is money itself!": The practical materiality of Bitcoin. Social Semiotics, 23(2), 261-277. http://doi.org/10.1080/10350330.2013.777594

Meiklejohn, S., Pomarole, M., Jordan, G., Levchenko, K., McCoy, D., Voelker, G. M., \& Savage, S. (2013). A fistful of Bitcoins: Characterizing payments among men with no names. Proceedings of the Internet Measurement Conference - IMC '13, (6), 127-140. http://doi.org/10.1145/2504730.2504747

Miers, I., Garman, C., Green, M., \& Rubin, A. D. (2013). Zerocoin: Anonymous distributed e-cash from bitcoin. Proceedings - IEEE Symposium on Security and Privacy, 397-411. http://doi.org/10.1109/SP.2013.34

Moser, M., Bohme, R., \& Breuker, D. (2013). An inquiry into money laundering tools in the Bitcoin ecosystem. ECrime Researchers Summit, ECrime. http://doi.org/10.1109/eCRS.2013.6805780

Nakamoto, S. (2008). Bitcoin: A Peer-to-Peer Electronic Cash System. Www.Bitcoin.Org, 9. http://doi.org/10.1007/s10838-008-9062-0

Nielsen, J. (2005). Ten Usability Heuristics. Communications of the ACM, 3(1990), 1-2. http://doi.org/10.1145/259963.260531

Nielsen, J. (2012). Usability 101: Introduction to Usability. Nielsen Norman Group, Articles. http://doi.org/10.1145/1268577.1268585

Ober, M., Katzenbeisser, S., \& Hamacher, K. (2013). Structure and anonymity of the bitcoin transaction graph. Future Internet, 5(2), 237-250. http://doi.org/10.3390/?5020237

Papadomichelaki, X., \& Mentzas, G. (2012). e-GovQual: A multiple-item scale for assessing e-government service quality. Government Information Quarterly, 29(1), 98-109. http://doi.org/10.1016/j.giq.2011.08.011

Plassaras, N. a. (2013). Regulating Digital Currencies: Bringing Bitcoin within the Reach of the IMF. Chicago Journal of International Law, 14(1), 377-407. http://doi.org/10.1525/sp.2007.54.1.23.

Raptis, D., Tselios, N., Kjeldskov, J., \& Skov, M. B. (2013). Does Size Matter? Investigating the Impact of Mobile Phone Screen Size on Users' Perceived Usability, Effectiveness and Efficiency. Proceedings of the International Conference on Human-Computer Interaction with Mobile Devices and Services (MobileHCI '13), 127-136. http://doi.org/10.1145/2493190.2493204

Reid, F., \& Harrigan, M. (2013). An analysis of anonymity in the bitcoin system. Security and Privacy in Social Networks, 197-223. http://doi.org/10.1007/978-1-4614-4139-7_10

Ruba, A., Hartmut, H., \& Viswanath, V. (2014). A Usability Evaluation of the Obamacare Website. Government Information Quarterly, 31(4), 669-680. http://doi.org/10.1016/j.giq.2014.07.003

Sas, C., \& Khairuddin, I. E. (2015). Exploring Trust in Bitcoin Technology: A Framework for HCI Research. Proceedings of the Annual Meeting of the Australian Special Interest Group for Computer Human Interaction, 338-342. http://doi.org/10.1145/2838739.2838821

Siegel, S. (1956). Nonparametric Statistics for the Behavioral Sciences. MsGraw-Hill Series in Psychology, 323.

Simpson, A. (2014). Who will drastically innovate the usability of Bitcoin. Retrieved December 30, 2017, from https://www.quora.com/profile/Arianna-Simpson

Singh, P., Chandavarkar, B. R., Arora, S., \& Agrawal, N. (2013). Performance comparison of executing fast transactions in bitcoin network using verifiable code execution. 
Proceedings - 2nd International Conference on Advanced Computing, Networking and Security, ADCONS 2013, 193-198. http://doi.org/10.1109/ADCONS.2013.42

Skudnov, R. (2012). Bitcoin clients. Instructor, 3(12), 32. Retrieved from http://bitcoinmalaysia.com/wpcontent/uploads/2012/12/Bitcoin_Clients_Thesis_Skudnov_Rostislav.pdf

Taylor, P., Zhang, D., \& Adipat, B. (2009). Challenges, Methodologies, and Issues in the Usability Testing of Mobile Applications Challenges, Methodologies, and Issues in the Usability Testing of Mobile Applications. International Journal of Human Computer Interaction, 18(3, November 2014), 37-41. http://doi.org/10.1207/s15327590ijhc1803

Wankmueller, J. (2005). (12) UnIted States Patent, 2(12). http://doi.org/10.1126/science.Liquids

Wells, J. D., Campbell, D. E., Valacich, J. S., \& Featherman, M. (2010). The Effect of Perceived Novelty on the Adoption of Information Technology Innovations: A Risk/Reward Perspective. Decision Sciences, 41(4), 813-843. http://doi.org/10.1111/j.1540-5915.2010.00292.x

Wirtschaftsuniversität Wien. (2017). Blockchain 101 for Governments. The Committee of Experts on International Cooperation in Tax Matters: Fifteenth Session, (October). Retrieved from http://www.un.org/esa/ffd/wpcontent/uploads/2017/10/15STM_Blockchain-101.pdf

Yelowitz, A., \& Wilson, M. (2015). Characteristics of Bitcoin users: an analysis of Google search data. Applied Economics Letters, 4851(January), 1-7. http://doi.org/10.1080/13504851.2014.995359

Yelowitz, A., Wilson, M., Tschorsch, F., Scheuermann, B., Stelian Mihalas, Skudnov, R., ... 1KGmoGJZfGXFZHU9bKjQmaphYJy8wVVEeh. (2015). The Acceptance of Bitcoin in Indonesia: Extended TAM with IDT. Journal of Business and Management, 4(1), 2838. http://doi.org/10.1145/2838739.2838821

Yermack, D. (2013). "Is Bitcoin a real currency? National Bureau of Economic Research, Working Pa. Retrieved from http://www.nber.org/papers/w19747 


\section{$\underline{\text { Appendix A }}$}

\section{Bitcoin Wallet Questionnaire}

Please choose the one most appropriate response to each statement

\begin{tabular}{|c|c|c|c|c|c|c|}
\hline \multicolumn{7}{|c|}{ Personal information } \\
\hline \multirow{2}{*}{$\begin{array}{l}\text { No } \\
1\end{array}$} & \multicolumn{6}{|c|}{ Please select the most appropriate answer } \\
\hline & Please select your gender: & Male & Female & Other & \multicolumn{2}{|c|}{ Prefer not to say } \\
\hline 2 & Please select your age: & $19-24$ & $25-29$ & $30-34$ & \multicolumn{2}{|l|}{$35-39$} \\
\hline 3 & $\begin{array}{l}\text { Please select your educational } \\
\text { level: }\end{array}$ & $1^{\text {st }}$ year & $2^{\text {nd }}$ Year & $3^{\text {rd }}$ Year & \multicolumn{2}{|c|}{ Bachelor degree } \\
\hline 4 & $\begin{array}{l}\text { How do you access Internet } \\
\text { services? }\end{array}$ & Smartphone & Tablet & Laptop & \multicolumn{2}{|c|}{ Desktop computer } \\
\hline \multicolumn{7}{|c|}{ Usability Evaluation } \\
\hline & Learnability & \begin{tabular}{|l|l|} 
Strongly \\
Agree
\end{tabular} & Agree & Neutral & Disagree & $\begin{array}{l}\text { Strongly } \\
\text { Disagree }\end{array}$ \\
\hline \multicolumn{7}{|c|}{ To what extent do you agree with the following statements? } \\
\hline 5 & $\begin{array}{l}\text { I can easily create and setup my own } \\
\text { Bitcoin Wallet account }\end{array}$ & $\Delta$ & $\Delta$ & $\Delta$ & $\Delta$ & $\Delta$ \\
\hline 6 & $\begin{array}{l}\text { I can easily find my Bitcoin Wallet } \\
\text { address. }\end{array}$ & $\Delta$ & $\Delta$ & $\Delta$ & $\Delta$ & $\Delta$ \\
\hline 7 & $\begin{array}{l}\text { I can easily locate the names and } \\
\text { functions on Bitcoin Wallet }\end{array}$ & $\Delta$ & $\Delta$ & $\Delta$ & $\Delta$ & $\Delta$ \\
\hline 8 & The help messages of Bitcoin Wallet & $\Delta$ & $\Delta$ & $\Delta$ & $\Delta$ & $\Delta$ \\
\hline
\end{tabular}




\begin{tabular}{|c|c|c|c|c|c|c|}
\hline & are NOT helpful. & & & & & \\
\hline 9 & I can easily view my coin balance. & $\Delta$ & $\Delta$ & $\Delta$ & $\Delta$ & $\Delta$ \\
\hline 10 & $\begin{array}{l}\text { I can easily view my Bitcoin address } \\
\text { book. }\end{array}$ & $\Delta$ & $\Delta$ & $\Delta$ & $\Delta$ & $\Delta$ \\
\hline 11 & $\begin{array}{l}\text { I can easily find the confirmed } \\
\text { transactions in my Bitcoin wallet. }\end{array}$ & $\Delta$ & $\Delta$ & $\Delta$ & $\Delta$ & $\Delta$ \\
\hline 12 & I can easily and quickly send money. & $\Delta$ & $\Delta$ & $\Delta$ & $\Delta$ & $\Delta$ \\
\hline \multicolumn{2}{|c|}{ Efficiency } & $\begin{array}{l}\text { Strongly } \\
\text { Agree }\end{array}$ & Agree & Neutral & Disagree & $\begin{array}{l}\text { Strongly } \\
\text { Disagree }\end{array}$ \\
\hline \multicolumn{7}{|c|}{ To what extent do you agree with the following statements? } \\
\hline 13 & $\begin{array}{l}\text { I can create a Bitcoin Wallet account in } \\
\text { no time. }\end{array}$ & $\Delta$ & $\Delta$ & $\Delta$ & $\Delta$ & $\Delta$ \\
\hline 14 & $\begin{array}{l}\text { I find the sequence of screens when } \\
\text { creating my wallet account confusing. }\end{array}$ & $\Delta$ & $\Delta$ & $\Delta$ & $\Delta$ & $\Delta$ \\
\hline 15 & $\begin{array}{l}\text { I can efficiently send payment using the } \\
\text { Quick Send option. }\end{array}$ & $\Delta$ & $\Delta$ & $\Delta$ & $\Delta$ & $\Delta$ \\
\hline 16 & $\begin{array}{l}\text { I can efficiently create a payment } \\
\text { request. }\end{array}$ & $\Delta$ & $\Delta$ & $\Delta$ & $\Delta$ & $\Delta$ \\
\hline 17 & $\begin{array}{l}\text { I can efficiently enable two factor } \\
\text { authentications on my wallet account. }\end{array}$ & $\Delta$ & $\Delta$ & $\Delta$ & $\Delta$ & $\Delta$ \\
\hline 18 & $\begin{array}{l}\text { I can efficiently send coins by mail and } \\
\text { SMS. }\end{array}$ & $\Delta$ & $\Delta$ & $\Delta$ & $\Delta$ & $\Delta$ \\
\hline 19 & I found the Bitcoin Wallet fast to use. & $\Delta$ & $\Delta$ & $\Delta$ & $\Delta$ & $\Delta$ \\
\hline 20 & $\begin{array}{l}\text { I can efficiently back up my wallet } \\
\text { using the available options. }\end{array}$ & $\Delta$ & $\Delta$ & $\Delta$ & $\Delta$ & $\Delta$ \\
\hline 21 & $\begin{array}{l}\text { On average, I have to do many clicks to } \\
\text { navigate my wallet }\end{array}$ & $\Delta$ & $\Delta$ & $\Delta$ & $\Delta$ & $\Delta$ \\
\hline 22 & $\begin{array}{l}\text { Overall, I can efficiently change my } \\
\text { account settings. }\end{array}$ & $\Delta$ & $\Delta$ & $\Delta$ & $\Delta$ & $\Delta$ \\
\hline 23 & $\begin{array}{l}\text { Overall, I was able to complete the } \\
\text { tasks and scenarios quickly and } \\
\text { accurately. }\end{array}$ & $\Delta$ & $\Delta$ & $\Delta$ & $\Delta$ & $\Delta$ \\
\hline \multicolumn{2}{|c|}{ Memorability } & $\begin{array}{l}\text { Strongly } \\
\text { Agree }\end{array}$ & Agree & Neutral & Disagree & $\begin{array}{l}\text { Strongly } \\
\text { Disagree }\end{array}$ \\
\hline \multicolumn{7}{|c|}{ To what extent do you agree with the following statements? } \\
\hline 24 & $\begin{array}{l}\text { I can easily remember the steps } \\
\text { required to create a Bitcoin Wallet } \\
\text { account. }\end{array}$ & $\Delta$ & $\Delta$ & $\Delta$ & $\Delta$ & $\Delta$ \\
\hline 25 & $\begin{array}{l}\text { I can easily remember the steps } \\
\text { required to change the settings of my } \\
\text { Bitcoin Wallet account. }\end{array}$ & $\Delta$ & $\Delta$ & $\Delta$ & $\Delta$ & $\Delta$ \\
\hline 26 & $\begin{array}{l}\text { I can easily remember the steps } \\
\text { required to send a payment through my } \\
\text { Bitcoin Wallet account. }\end{array}$ & $\Delta$ & $\Delta$ & $\Delta$ & $\Delta$ & $\Delta$ \\
\hline 27 & $\begin{array}{l}\text { I can recall the steps required to change } \\
\text { my Bitcoin Wallet address. }\end{array}$ & $\Delta$ & $\Delta$ & $\Delta$ & $\Delta$ & $\Delta$ \\
\hline 28 & $\begin{array}{l}\text { I can recall the steps required to change } \\
\text { my Bitcoin Wallet security settings. }\end{array}$ & $\Delta$ & $\Delta$ & $\Delta$ & $\Delta$ & $\Delta$ \\
\hline 29 & $\begin{array}{l}\text { I can recall the steps needed to change } \\
\text { the time of inactivity logout. }\end{array}$ & $\Delta$ & $\Delta$ & $\Delta$ & $\Delta$ & $\Delta$ \\
\hline 30 & $\begin{array}{l}\text { I can remember the steps required to } \\
\text { change notification options when a } \\
\text { payment is sent or received from my } \\
\text { wallet. }\end{array}$ & $\Delta$ & $\Delta$ & $\Delta$ & $\Delta$ & $\Delta$ \\
\hline 31 & $\begin{array}{l}\text { It is hard to remember the secret phrase } \\
\text { that is used to help verify my identity in } \\
\text { case of losing the wallet identifier. }\end{array}$ & $\Delta$ & $\Delta$ & $\Delta$ & $\Delta$ & $\Delta$ \\
\hline
\end{tabular}




\begin{tabular}{|c|c|c|c|c|c|c|}
\hline \multicolumn{2}{|c|}{ Error \& Recoverability } & $\begin{array}{l}\text { Strongly } \\
\text { Agree }\end{array}$ & Agree & Neutral & Disagree & $\begin{array}{l}\text { Strongly } \\
\text { Disagree }\end{array}$ \\
\hline \multicolumn{7}{|c|}{ To what extent do you agree with the following statements? } \\
\hline 32 & $\begin{array}{l}\text { It is difficult to make errors in an action } \\
\text { because Bitcoin Wallet does not allow } \\
\text { me to skip or ignore any of the steps. }\end{array}$ & $\Delta$ & $\Delta$ & $\Delta$ & $\Delta$ & $\Delta$ \\
\hline 33 & $\begin{array}{l}\text { It is easy to miss out notifications or } \\
\text { messages when using Bitcoin Wallet } \\
\text { frequently. }\end{array}$ & $\Delta$ & $\Delta$ & $\Delta$ & $\Delta$ & $\Delta$ \\
\hline 34 & $\begin{array}{l}\text { It is easy to see errors because the } \\
\text { Bitcoin wallet indicates a highlighted } \\
\text { message around errors. }\end{array}$ & $\Delta$ & $\Delta$ & $\Delta$ & $\Delta$ & $\Delta$ \\
\hline 35 & $\begin{array}{l}\text { It is easy to fill in the Bitcoin address in } \\
\text { address field when transfer coins to } \\
\text { other address. }\end{array}$ & $\Delta$ & $\Delta$ & $\Delta$ & $\Delta$ & $\Delta$ \\
\hline 36 & $\begin{array}{l}\text { I can clearly see the progress in an } \\
\text { action as the whole process is indicated. }\end{array}$ & $\Delta$ & $\Delta$ & $\Delta$ & $\Delta$ & $\Delta$ \\
\hline 37 & $\begin{array}{l}\text { It is easy to recover my Bitcoin Wallet } \\
\text { login password. }\end{array}$ & $\Delta$ & $\Delta$ & $\Delta$ & $\Delta$ & $\Delta$ \\
\hline 38 & $\begin{array}{l}\text { It is hard to recover my Bitcoin Wallet } \\
\text { login password. }\end{array}$ & $\Delta$ & $\Delta$ & $\Delta$ & $\Delta$ & $\Delta$ \\
\hline 39 & $\begin{array}{l}\text { It is not easy to reverse any transaction } \\
\text { with Bitcoin wallet }\end{array}$ & $\Delta$ & $\Delta$ & $\Delta$ & $\Delta$ & $\Delta$ \\
\hline 40 & $\begin{array}{l}\text { Error messages are easy to read and } \\
\text { understand. }\end{array}$ & & & & & \\
\hline & Help \& Training & $\begin{array}{l}\text { Strongly } \\
\text { Agree }\end{array}$ & Agree & Neutral & Disagree & $\begin{array}{l}\text { Strongly } \\
\text { Disagree }\end{array}$ \\
\hline \multicolumn{7}{|c|}{ To what extent do you agree with the following statements? } \\
\hline 41 & $\begin{array}{l}\text { I can easily use the online help to find } \\
\text { the relevant answer to solve the } \\
\text { problems. }\end{array}$ & $\Delta$ & $\Delta$ & $\Delta$ & $\Delta$ & $\Delta$ \\
\hline 42 & $\begin{array}{l}\text { It is easy to find the help option when I } \\
\text { needed. }\end{array}$ & $\Delta$ & $\Delta$ & $\Delta$ & $\Delta$ & $\Delta$ \\
\hline 43 & $\begin{array}{l}\text { It is easy to switch between the online } \\
\text { help and my current work while using } \\
\text { Bitcoin Wallet. }\end{array}$ & $\Delta$ & $\Delta$ & $\Delta$ & $\Delta$ & $\Delta$ \\
\hline 44 & $\begin{array}{l}\text { The training provided to use Bitcoin } \\
\text { Wallet is useful and easy to understand. }\end{array}$ & $\Delta$ & $\Delta$ & $\Delta$ & $\Delta$ & $\Delta$ \\
\hline 45 & $\begin{array}{l}\text { Overall, the information provided with } \\
\text { Bitcoin Wallet (such as online help, on- } \\
\text { screen messages, and other } \\
\text { documentation) is clear. }\end{array}$ & $\Delta$ & $\Delta$ & $\Delta$ & $\Delta$ & $\Delta$ \\
\hline Sec & & $\begin{array}{l}\text { Strongly } \\
\text { Agree }\end{array}$ & Agree & Neutral & Disagree & $\begin{array}{l}\text { Strongly } \\
\text { Disagree }\end{array}$ \\
\hline \multicolumn{7}{|c|}{ To what extent do you agree with the following statements? } \\
\hline 46 & $\begin{array}{l}\text { I can easily learn to use the security } \\
\text { functions of Bitcoin wallet. }\end{array}$ & $\Delta$ & $\Delta$ & $\Delta$ & $\Delta$ & $\Delta$ \\
\hline 47 & $\begin{array}{l}\text { I can easily find the security functions } \\
\text { grouped into logical zones, and there } \\
\text { are headings used to separate the zones. }\end{array}$ & $\Delta$ & $\Delta$ & $\Delta$ & $\Delta$ & $\Delta$ \\
\hline
\end{tabular}




\begin{tabular}{|c|c|c|c|c|c|c|}
\hline 48 & $\begin{array}{l}\text { I can easily find and change the } \\
\text { security selection defaults. }\end{array}$ & $\Delta$ & $\Delta$ & $\Delta$ & $\Delta$ & $\Delta$ \\
\hline 49 & $\begin{array}{l}\text { I can easily change the level of security } \\
\text { detail. }\end{array}$ & $\Delta$ & $\Delta$ & $\Delta$ & $\Delta$ & $\Delta$ \\
\hline 50 & $\begin{array}{l}\text { I can easily change between novice and } \\
\text { expert security levels. }\end{array}$ & $\Delta$ & $\Delta$ & $\Delta$ & $\Delta$ & $\Delta$ \\
\hline 51 & $\begin{array}{l}\text { Bitcoin Wallet grants me access to my } \\
\text { account based on various } \\
\text { authentications, such as password, } \\
\text { biometrics and SMS one-time } \\
\text { passwords (OTP). }\end{array}$ & $\Delta$ & $\Delta$ & $\Delta$ & $\Delta$ & $\Delta$ \\
\hline 52 & $\begin{array}{l}\text { I feel in control over the situation when } \\
\text { using Bitcoin Wallet. }\end{array}$ & $\Delta$ & $\Delta$ & $\Delta$ & $\Delta$ & $\Delta$ \\
\hline 53 & $\begin{array}{l}\text { I can easily access protected or } \\
\text { confidential areas without certain } \\
\text { passwords. }\end{array}$ & $\Delta$ & $\Delta$ & $\Delta$ & $\Delta$ & $\Delta$ \\
\hline 54 & $\begin{array}{l}\text { Bitcoin Wallet warns me if I am about } \\
\text { to do any security breaches. }\end{array}$ & $\Delta$ & $\Delta$ & $\Delta$ & $\Delta$ & $\Delta$ \\
\hline 55 & $\begin{array}{l}\text { Bitcoin Wallet notifies me about my } \\
\text { access privileges. }\end{array}$ & $\Delta$ & $\Delta$ & $\Delta$ & $\Delta$ & $\Delta$ \\
\hline 56 & $\begin{array}{l}\text { I can easily cancel any security } \\
\text { operations in progress. }\end{array}$ & $\Delta$ & $\Delta$ & $\Delta$ & $\Delta$ & $\Delta$ \\
\hline 57 & $\begin{array}{l}\text { I can easily understand the language } \\
\text { used relating to security functions. }\end{array}$ & $\Delta$ & $\Delta$ & $\Delta$ & $\Delta$ & $\Delta$ \\
\hline 58 & $\begin{array}{l}\text { Overall, I am satisfied with the security } \\
\text { options provided by Bitcoin Wallet. }\end{array}$ & $\Delta$ & $\Delta$ & $\Delta$ & $\Delta$ & $\Delta$ \\
\hline 59 & $\begin{array}{l}\text { Overall, I am satisfied with the level of } \\
\text { security provided by Bitcoin Wallet. }\end{array}$ & $\Delta$ & $\Delta$ & $\Delta$ & $\Delta$ & $\Delta$ \\
\hline 60 & $\begin{array}{l}\text { Overall, I am satisfied with the } \\
\text { protection provided by Bitcoin Wallet } \\
\text { to ensure my privacy. }\end{array}$ & $\Delta$ & $\Delta$ & $\Delta$ & $\Delta$ & $\Delta$ \\
\hline 61 & $\begin{array}{l}\text { Overall, I am satisfied with the } \\
\text { anonymity provided by Bitcoin Wallet. }\end{array}$ & $\Delta$ & $\Delta$ & $\Delta$ & $\Delta$ & $\Delta$ \\
\hline \multicolumn{2}{|c|}{ Subjective Satisfaction } & $\begin{array}{l}\text { Strongly } \\
\text { Agree }\end{array}$ & Agree & Neutral & Disagree & $\begin{array}{l}\text { Strongly } \\
\text { Disagree } \\
\end{array}$ \\
\hline \multicolumn{7}{|c|}{ To what extent do you agree with the following statements? } \\
\hline 62 & $\begin{array}{l}\text { Overall, I am satisfied with the level of } \\
\text { anonymity provided by Bitcoin Wallet. }\end{array}$ & $\Delta$ & $\Delta$ & $\Delta$ & $\Delta$ & $\Delta$ \\
\hline 63 & $\begin{array}{l}\text { Overall, I am satisfied with how easy it } \\
\text { is to use Bitcoin Wallet. }\end{array}$ & $\Delta$ & $\Delta$ & $\Delta$ & $\Delta$ & $\Delta$ \\
\hline 65 & It is simple to use this system. & $\Delta$ & $\Delta$ & $\Delta$ & $\Delta$ & $\Delta$ \\
\hline 66 & $\begin{array}{l}\text { I could effectively complete the tasks } \\
\text { using Bitcoin Wallet. }\end{array}$ & $\Delta$ & $\Delta$ & $\Delta$ & $\Delta$ & $\Delta$ \\
\hline 67 & $\begin{array}{l}\text { I am happy about the speed and } \\
\text { accuracy to complete the tasks using } \\
\text { Bitcoin Wallet. }\end{array}$ & $\Delta$ & $\Delta$ & $\Delta$ & $\Delta$ & $\Delta$ \\
\hline 68 & I felt comfortable using Bitcoin Wallet. & $\Delta$ & $\Delta$ & $\Delta$ & $\Delta$ & $\Delta$ \\
\hline 69 & $\begin{array}{l}\text { It was easy to learn to use Bitcoin } \\
\text { Wallet. }\end{array}$ & $\Delta$ & $\Delta$ & $\Delta$ & $\Delta$ & $\Delta$ \\
\hline
\end{tabular}




\begin{tabular}{|c|c|c|c|c|c|c|}
\hline 70 & $\begin{array}{l}\text { I believe I could become productive } \\
\text { quickly using Bitcoin Wallet. }\end{array}$ & $\Delta$ & $\Delta$ & $\Delta$ & $\Delta$ & $\Delta$ \\
\hline 71 & $\begin{array}{l}\text { The Bitcoin Wallet client shows error } \\
\text { messages that clearly indicate how to } \\
\text { fix problems. }\end{array}$ & $\Delta$ & $\Delta$ & $\Delta$ & $\Delta$ & $\Delta$ \\
\hline 72 & $\begin{array}{l}\text { Whenever I made a mistake using the } \\
\text { Bitcoin Wallet, I could recover easily } \\
\text { and quickly. }\end{array}$ & $\Delta$ & $\Delta$ & $\Delta$ & $\Delta$ & $\Delta$ \\
\hline 73 & $\begin{array}{l}\text { It was easy to find the information I } \\
\text { needed. }\end{array}$ & $\Delta$ & $\Delta$ & $\Delta$ & $\Delta$ & $\Delta$ \\
\hline 74 & $\begin{array}{l}\text { The information provided for Bitcoin } \\
\text { Wallet was easy to understand. }\end{array}$ & $\Delta$ & $\Delta$ & $\Delta$ & $\Delta$ & $\Delta$ \\
\hline 75 & $\begin{array}{l}\text { The information was effective in } \\
\text { helping me complete the tasks. }\end{array}$ & $\Delta$ & $\Delta$ & $\Delta$ & $\Delta$ & $\Delta$ \\
\hline 76 & $\begin{array}{l}\text { The organisation of information on } \\
\text { Bitcoin Wallet screens is clear. }\end{array}$ & $\Delta$ & $\Delta$ & $\Delta$ & $\Delta$ & $\Delta$ \\
\hline 77 & $\begin{array}{l}\text { The interface of Bitcoin Wallet is } \\
\text { pleasant. }\end{array}$ & $\Delta$ & $\Delta$ & $\Delta$ & $\Delta$ & $\Delta$ \\
\hline 78 & $\begin{array}{l}\text { I liked using the interface of Bitcoin } \\
\text { Wallet. }\end{array}$ & $\Delta$ & $\Delta$ & $\Delta$ & $\Delta$ & $\Delta$ \\
\hline 79 & $\begin{array}{l}\text { Bitcoin Wallet client has all the } \\
\text { functions and capabilities I expect it to } \\
\text { have. }\end{array}$ & $\Delta$ & $\Delta$ & $\Delta$ & $\Delta$ & $\Delta$ \\
\hline 80 & $\begin{array}{l}\text { Overall, I am satisfied with Bitcoin } \\
\text { Wallet. }\end{array}$ & $\Delta$ & $\Delta$ & $\Delta$ & $\Delta$ & $\Delta$ \\
\hline
\end{tabular}

\section{Appendix B}

\section{Credit card questionnaire (Part two)}

\begin{tabular}{|c|c|c|c|c|c|c|}
\hline \multicolumn{7}{|c|}{ Personal information } \\
\hline \multirow{2}{*}{$\begin{array}{l}\text { No } \\
1\end{array}$} & \multicolumn{6}{|c|}{ Please select the most appropriate answer } \\
\hline & Please select your gender: & Male & Female & Other & \multicolumn{2}{|c|}{ Prefer not to say } \\
\hline 2 & Please select your age: & $19-24$ & $25-29$ & $30-34$ & \multicolumn{2}{|l|}{$35-39$} \\
\hline 3 & $\begin{array}{l}\text { Please select your educational } \\
\text { level: }\end{array}$ & $1^{\text {st }}$ year & $2^{\text {nd }}$ Year & $3^{\text {rd }}$ Year & \multicolumn{2}{|c|}{ Bachelor degree } \\
\hline 4 & $\begin{array}{l}\text { How do you access Internet } \\
\text { services? }\end{array}$ & Smartphone & Tablet & Laptop & \multicolumn{2}{|c|}{ Desktop computer } \\
\hline \multicolumn{7}{|c|}{ Usability Evaluation } \\
\hline & Learnability & 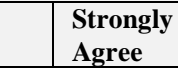 & Agree & Neutral & Disagree & $\begin{array}{l}\text { Strongly } \\
\text { Disagree }\end{array}$ \\
\hline \multicolumn{7}{|c|}{ To what extent do you agree with the following statements? } \\
\hline 5 & $\begin{array}{l}\text { I can easily conduct online payment } \\
\text { transactions using my credit or debit } \\
\text { card. }\end{array}$ & $\Delta$ & $\Delta$ & $\Delta$ & $\Delta$ & $\Delta$ \\
\hline 6 & I can quickly conduct online paymen & $\Delta$ & $\Delta$ & $\Delta$ & $\Delta$ & $\Delta$ \\
\hline
\end{tabular}




\begin{tabular}{|c|c|c|c|c|c|c|}
\hline & using my credit or debit card. & & & & & \\
\hline 7 & $\begin{array}{l}\text { I can easily fill in the credit or debit } \\
\text { card online form to make payment. }\end{array}$ & $\Delta$ & $\Delta$ & $\Delta$ & $\Delta$ & $\Delta$ \\
\hline 8 & $\begin{array}{l}\text { I can easily fill in various online forms } \\
\text { to make online payments using my } \\
\text { credit or debit card. }\end{array}$ & $\Delta$ & $\Delta$ & $\Delta$ & $\Delta$ & $\Delta$ \\
\hline 9 & $\begin{array}{l}\text { I find it easy to understand credit or } \\
\text { debit card online payment forms. }\end{array}$ & $\Delta$ & $\Delta$ & $\Delta$ & $\Delta$ & $\Delta$ \\
\hline 10 & $\begin{array}{l}\text { The help messages for credit or debit } \\
\text { cards are helpful. }\end{array}$ & $\Delta$ & $\Delta$ & $\Delta$ & $\Delta$ & $\Delta$ \\
\hline 11 & $\begin{array}{l}\text { I know if the online transaction is } \\
\text { successful or not when I conduct a } \\
\text { transaction using my credit or debit } \\
\text { card. }\end{array}$ & $\Delta$ & $\Delta$ & $\Delta$ & $\Delta$ & $\Delta$ \\
\hline 12 & $\begin{array}{l}\text { I can easily cancel any online } \\
\text { transaction when using my credit or } \\
\text { debit card. }\end{array}$ & $\Delta$ & $\Delta$ & $\Delta$ & $\Delta$ & $\Delta$ \\
\hline 13 & $\begin{array}{l}\text { It is easy to find out about my } \\
\text { confirmed transactions when using my } \\
\text { credit or debit card. }\end{array}$ & $\Delta$ & $\Delta$ & $\Delta$ & $\Delta$ & $\Delta$ \\
\hline \multicolumn{2}{|c|}{ Efficiency } & $\begin{array}{l}\text { Strongly } \\
\text { Agree }\end{array}$ & Agree & Neutral & Disagree & $\begin{array}{l}\text { Strongly } \\
\text { Disagree }\end{array}$ \\
\hline \multicolumn{7}{|c|}{ To what extent do you agree with the following statements? } \\
\hline 14 & $\begin{array}{l}\text { I can efficiently conduct any online } \\
\text { transaction with my credit or debit card. }\end{array}$ & $\Delta$ & $\Delta$ & $\Delta$ & $\Delta$ & $\Delta$ \\
\hline 15 & $\begin{array}{l}\text { I find filling in forms when conducting } \\
\text { online payments using my credit or } \\
\text { debit card confusing. }\end{array}$ & $\Delta$ & $\Delta$ & $\Delta$ & $\Delta$ & $\Delta$ \\
\hline 16 & $\begin{array}{l}\text { I can efficiently conduct small amount } \\
\text { online payment (e.g. £1) using my } \\
\text { credit or debit card. }\end{array}$ & $\Delta$ & $\Delta$ & $\Delta$ & $\Delta$ & $\Delta$ \\
\hline 18 & $\begin{array}{l}\text { I can efficiently follow the sequence of } \\
\text { the filling in forms when conducting } \\
\text { online transactions with my credit or } \\
\text { debit card. }\end{array}$ & $\Delta$ & $\Delta$ & $\Delta$ & $\Delta$ & $\Delta$ \\
\hline 19 & $\begin{array}{l}\text { On average, I have to do many clicks to } \\
\text { conduct an online payment using my } \\
\text { credit or debit card. }\end{array}$ & $\Delta$ & $\Delta$ & $\Delta$ & $\Delta$ & $\Delta$ \\
\hline 20 & $\begin{array}{l}\text { Overall, I find it convenient to transact } \\
\text { online with my credit or debit card over } \\
\text { another payment method because it's } \\
\text { easier to use. }\end{array}$ & $\Delta$ & $\Delta$ & $\Delta$ & $\Delta$ & $\Delta$ \\
\hline 21 & $\begin{array}{l}\text { Overall, I can transact and conduct } \\
\text { online payment using my credit or debit } \\
\text { card easily. }\end{array}$ & $\Delta$ & $\Delta$ & $\Delta$ & $\Delta$ & $\Delta$ \\
\hline \multicolumn{2}{|c|}{ Memorability } & $\begin{array}{l}\text { Strongly } \\
\text { Agree }\end{array}$ & Agree & Neutral & Disagree & $\begin{array}{l}\text { Strongly } \\
\text { Disagree }\end{array}$ \\
\hline \multicolumn{7}{|c|}{ To what extent do you agree with the following statements? } \\
\hline 22 & $\begin{array}{l}\text { I can easily remember the steps } \\
\text { required to conduct online payment } \\
\text { using my credit or debit card. }\end{array}$ & $\Delta$ & $\Delta$ & $\Delta$ & $\Delta$ & $\Delta$ \\
\hline 24 & $\begin{array}{l}\text { I can easily remember the sequence for } \\
\text { conducting online transactions using } \\
\text { my credit or debit card. }\end{array}$ & $\Delta$ & $\Delta$ & $\Delta$ & $\Delta$ & $\Delta$ \\
\hline 25 & I can easily remember the pin code of & $\Delta$ & $\Delta$ & $\Delta$ & $\Delta$ & $\Delta$ \\
\hline
\end{tabular}




\begin{tabular}{|c|c|c|c|c|c|c|}
\hline & $\begin{array}{l}\text { my credit or debit card to authorise } \\
\text { transactions. }\end{array}$ & & & & & \\
\hline 26 & $\begin{array}{l}\text { I can recall the steps required to change } \\
\text { the pin number of my credit or debit } \\
\text { card. }\end{array}$ & $\Delta$ & $\Delta$ & $\Delta$ & $\Delta$ & $\Delta$ \\
\hline \multicolumn{2}{|c|}{ Error \& Recoverability } & $\begin{array}{l}\text { Strongly } \\
\text { Agree }\end{array}$ & Agree & Neutral & Disagree & $\begin{array}{l}\text { Strongly } \\
\text { Disagree }\end{array}$ \\
\hline \multicolumn{7}{|c|}{ To what extent do you agree with the following statements? } \\
\hline 27 & $\begin{array}{l}\text { It is difficult to make errors in filling in } \\
\text { the online form when conducting online } \\
\text { transactions by credit or debit card. }\end{array}$ & $\Delta$ & $\Delta$ & $\Delta$ & $\Delta$ & $\Delta$ \\
\hline 28 & $\begin{array}{l}\text { It is easy to miss out notifications or } \\
\text { messages when conducting online } \\
\text { transactions using my credit or debit } \\
\text { card. }\end{array}$ & $\Delta$ & $\Delta$ & $\Delta$ & $\Delta$ & $\Delta$ \\
\hline 29 & $\begin{array}{l}\text { It is easy to see errors when filling in } \\
\text { the online credit or debit card form and } \\
\text { a highlighted message is shown around } \\
\text { errors. }\end{array}$ & $\Delta$ & $\Delta$ & $\Delta$ & $\Delta$ & $\Delta$ \\
\hline 30 & $\begin{array}{l}\text { It is easy to fill the in the right data in a } \\
\text { data entry field because the number of } \\
\text { character spaces available in a field is } \\
\text { indicated. }\end{array}$ & $\Delta$ & $\Delta$ & $\Delta$ & $\Delta$ & $\Delta$ \\
\hline 31 & $\begin{array}{l}\text { I can clearly see the progress in an } \\
\text { action as the whole process is indicated. }\end{array}$ & $\Delta$ & $\Delta$ & $\Delta$ & $\Delta$ & $\Delta$ \\
\hline 32 & $\begin{array}{l}\text { It is easy to recover my credit or debit } \\
\text { card security number. }\end{array}$ & $\Delta$ & $\Delta$ & $\Delta$ & $\Delta$ & $\Delta$ \\
\hline 33 & $\begin{array}{l}\text { It is hard to reverse any payment or } \\
\text { transaction conducted by debit or credit } \\
\text { card. }\end{array}$ & $\Delta$ & $\Delta$ & $\Delta$ & $\Delta$ & $\Delta$ \\
\hline & Help \& Training & $\begin{array}{l}\text { Strongly } \\
\text { Agree }\end{array}$ & Agree & Neutral & Disagree & $\begin{array}{l}\text { Strongly } \\
\text { Disagree }\end{array}$ \\
\hline \multicolumn{7}{|c|}{ To what extent do you agree with the following statements? } \\
\hline 34 & $\begin{array}{l}\text { I can easily use online help to find the } \\
\text { relevant answer to solve any problems. }\end{array}$ & $\Delta$ & $\Delta$ & $\Delta$ & $\Delta$ & $\Delta$ \\
\hline 35 & $\begin{array}{l}\text { It is easy to find the help option while } \\
\text { conducting transactions using my credit } \\
\text { or debit card. }\end{array}$ & $\Delta$ & $\Delta$ & $\Delta$ & $\Delta$ & $\Delta$ \\
\hline 36 & $\begin{array}{l}\text { The training provided to conduct online } \\
\text { transactions and filling in the credit or } \\
\text { debit card form is easy to understand. }\end{array}$ & $\Delta$ & $\Delta$ & $\Delta$ & $\Delta$ & $\Delta$ \\
\hline 37 & $\begin{array}{l}\text { Overall, the information provided } \\
\text { related to conducting online } \\
\text { transactions using credit or debit cards } \\
\text { (such as online help, on-screen } \\
\text { messages, and other documentation) is } \\
\text { clear. }\end{array}$ & $\Delta$ & $\Delta$ & $\Delta$ & $\Delta$ & $\Delta$ \\
\hline \multicolumn{2}{|r|}{ clear. } & $\begin{array}{l}\text { Strongly } \\
\text { Agree }\end{array}$ & Agree & Neutral & Disagree & $\begin{array}{l}\text { Strongly } \\
\text { Disagree }\end{array}$ \\
\hline \multicolumn{7}{|c|}{ To what extent do you agree with the following statements? } \\
\hline 38 & $\begin{array}{l}\text { I trust the total security provided by my } \\
\text { bank when conducting online }\end{array}$ & $\Delta$ & $\Delta$ & $\Delta$ & $\Delta$ & $\Delta$ \\
\hline
\end{tabular}




\begin{tabular}{|c|c|c|c|c|c|c|}
\hline & $\begin{array}{l}\text { transaction using my credit or debit } \\
\text { card }\end{array}$ & & & & & \\
\hline 39 & $\begin{array}{l}\text { I am very aware that banks or shops can } \\
\text { keep records about my payments when } \\
\text { I conduct transactions using my credit } \\
\text { or debit card. }\end{array}$ & $\Delta$ & $\Delta$ & $\Delta$ & $\Delta$ & $\Delta$ \\
\hline 40 & $\begin{array}{l}\text { I am comfortable with the security level } \\
\text { that is provided by my credit or debit } \\
\text { card issuer. }\end{array}$ & $\Delta$ & $\Delta$ & $\Delta$ & $\Delta$ & $\Delta$ \\
\hline 41 & $\begin{array}{l}\text { I feel in control over the situation when } \\
\text { conducting online transactions using } \\
\text { my credit or debit card. }\end{array}$ & $\Delta$ & $\Delta$ & $\Delta$ & $\Delta$ & $\Delta$ \\
\hline 42 & $\begin{array}{l}\text { When conducting online transactions } \\
\text { using my credit or debit card, I get } \\
\text { alerted about any security issues. }\end{array}$ & $\Delta$ & $\Delta$ & $\Delta$ & $\Delta$ & $\Delta$ \\
\hline 43 & $\begin{array}{l}\text { I can easily cancel any security } \\
\text { operations in progress. }\end{array}$ & $\Delta$ & $\Delta$ & $\Delta$ & $\Delta$ & $\Delta$ \\
\hline 44 & $\begin{array}{l}\text { I can easily understand the language } \\
\text { used relating to security issues. }\end{array}$ & $\Delta$ & $\Delta$ & $\Delta$ & $\Delta$ & $\Delta$ \\
\hline 45 & $\begin{array}{l}\text { Security awareness is provided when I } \\
\text { conduct online transactions or fill in the } \\
\text { credit or debit card form. }\end{array}$ & $\Delta$ & $\Delta$ & $\Delta$ & $\Delta$ & $\Delta$ \\
\hline 46 & $\begin{array}{l}\text { Overall, I am satisfied with the security } \\
\text { level provided by my credit or debit } \\
\text { card issuer. }\end{array}$ & $\Delta$ & $\Delta$ & $\Delta$ & $\Delta$ & $\Delta$ \\
\hline 47 & $\begin{array}{l}\text { Overall, I am satisfied with the level of } \\
\text { control provided when I transact using } \\
\text { my credit or debit card. }\end{array}$ & $\Delta$ & $\Delta$ & $\Delta$ & $\Delta$ & $\Delta$ \\
\hline 48 & $\begin{array}{l}\text { Overall, I am satisfied with the } \\
\text { protection provided by my credit or } \\
\text { debit card to ensure my privacy. }\end{array}$ & $\Delta$ & $\Delta$ & $\Delta$ & $\Delta$ & $\Delta$ \\
\hline \multicolumn{2}{|c|}{ Subjective Satisfaction } & $\begin{array}{l}\text { Strongly } \\
\text { Agree }\end{array}$ & Agree & Neutral & Disagree & $\begin{array}{l}\text { Strongly } \\
\text { Disagree }\end{array}$ \\
\hline \multicolumn{7}{|c|}{ Subjective Satisfaction } \\
\hline 49 & $\begin{array}{l}\text { Overall, I am satisfied using my credit } \\
\text { or debit card to do online transactions }\end{array}$ & $\Delta$ & $\Delta$ & $\Delta$ & $\Delta$ & $\Delta$ \\
\hline 50 & $\begin{array}{l}\text { Overall, I am satisfied with how easy it } \\
\text { is to use my credit or debit card for } \\
\text { online transactions }\end{array}$ & $\Delta$ & $\Delta$ & $\Delta$ & $\Delta$ & $\Delta$ \\
\hline 51 & $\begin{array}{l}\text { It is simple to fill in and use credit or } \\
\text { debit card online forms. }\end{array}$ & $\Delta$ & $\Delta$ & $\Delta$ & $\Delta$ & $\Delta$ \\
\hline 52 & $\begin{array}{l}\text { I can effectively transact using my } \\
\text { credit or debit card. }\end{array}$ & $\Delta$ & $\Delta$ & $\Delta$ & $\Delta$ & $\Delta$ \\
\hline 53 & $\begin{array}{l}\text { I am able to efficiently complete my } \\
\text { online transactions using credit or debit } \\
\text { card. }\end{array}$ & $\Delta$ & $\Delta$ & $\Delta$ & $\Delta$ & $\Delta$ \\
\hline 54 & $\begin{array}{l}\text { I felt comfortable using credit or debit } \\
\text { card. }\end{array}$ & $\Delta$ & $\Delta$ & $\Delta$ & $\Delta$ & $\Delta$ \\
\hline 55 & $\begin{array}{l}\text { It is easy to learn to use credit or debit } \\
\text { cards for online transactions. }\end{array}$ & $\Delta$ & $\Delta$ & $\Delta$ & $\Delta$ & $\Delta$ \\
\hline
\end{tabular}




\begin{tabular}{|c|c|c|c|c|c|c|}
\hline 56 & $\begin{array}{l}\text { I believe I could become productive } \\
\text { quickly using credit or debit cards for } \\
\text { conducting online transactions. }\end{array}$ & $\Delta$ & $\Delta$ & $\Delta$ & $\Delta$ & $\Delta$ \\
\hline 57 & $\begin{array}{l}\text { It is clearly indicated how to fix } \\
\text { problems when conducting online } \\
\text { transactions using my credit or debit } \\
\text { card. }\end{array}$ & $\Delta$ & $\Delta$ & $\Delta$ & $\Delta$ & $\Delta$ \\
\hline 58 & $\begin{array}{l}\text { It is easy and quick to recover from any } \\
\text { errors when conducting online } \\
\text { transactions using credit or debit card. }\end{array}$ & $\Delta$ & $\Delta$ & $\Delta$ & $\Delta$ & $\Delta$ \\
\hline 59 & $\begin{array}{l}\text { It is easy to find the information I need } \\
\text { to conduct online transactions using } \\
\text { credit or debit card. }\end{array}$ & $\Delta$ & $\Delta$ & $\Delta$ & $\Delta$ & $\Delta$ \\
\hline 60 & $\begin{array}{l}\text { The information provided when } \\
\text { conducting online transactions using } \\
\text { credit or debit card is easy to } \\
\text { understand. }\end{array}$ & $\Delta$ & $\Delta$ & $\Delta$ & $\Delta$ & $\Delta$ \\
\hline 61 & $\begin{array}{l}\text { Information is effective in helping me } \\
\text { to conduct online transactions using } \\
\text { credit or debit card. }\end{array}$ & $\Delta$ & $\Delta$ & $\Delta$ & $\Delta$ & $\Delta$ \\
\hline 62 & $\begin{array}{l}\text { The organisation of information } \\
\text { required to conduct online transactions } \\
\text { on the screens is clear. }\end{array}$ & $\Delta$ & $\Delta$ & $\Delta$ & $\Delta$ & $\Delta$ \\
\hline 63 & $\begin{array}{l}\text { Paying with credit or debit card online } \\
\text { is pleasant. }\end{array}$ & $\Delta$ & $\Delta$ & $\Delta$ & $\Delta$ & $\Delta$ \\
\hline 64 & $\begin{array}{l}\text { I like using credit or debit cards to } \\
\text { conduct online transactions. }\end{array}$ & $\Delta$ & $\Delta$ & $\Delta$ & $\Delta$ & $\Delta$ \\
\hline 65 & $\begin{array}{l}\text { All the functions and capabilities I } \\
\text { expect it to have to conduct online } \\
\text { transactions using credit or debit card } \\
\text { are useful. }\end{array}$ & $\Delta$ & $\Delta$ & $\Delta$ & $\Delta$ & $\Delta$ \\
\hline 66 & $\begin{array}{l}\text { Overall, I am satisfied with paying } \\
\text { online using credit or debit card. }\end{array}$ & $\Delta$ & $\Delta$ & $\Delta$ & $\Delta$ & $\Delta$ \\
\hline
\end{tabular}

